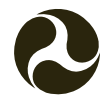

U.S. Department

of Transportation

National Highway

Traffic Safety

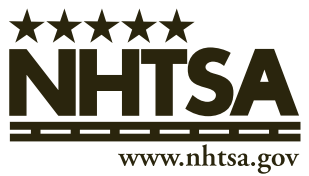

January 2015

\title{
Evaluation of ISO CRS Envelopes Relative to U.S. Vehicles and Child Restraint Systems
}




\section{DISCLAIMER}

This publication is distributed by the U.S. Department of Transportation, National Highway Traffic Safety Administration, in the interest of information exchange. The opinions, findings, and conclusions expressed in this publication are those of the authors and not necessarily those of the Department of Transportation or the National Highway Traffic Safety Administration. The United States Government assumes no liability for its contents or use thereof. If trade or manufacturers' names or products are mentioned, it is because they are considered essential to the object of the publication and should not be construed as an endorsement. The United States Government does not endorse products or manufacturers.

Suggested APA Format Citation:

Hu, J., Manary, M. A., Klinich, K. D., \& Reed, M. P. (2015, January). Evaluation of ISO CRS envelopes relative to U.S. vehicles and child restraint systems. (Report No. DOT HS 812 106). Washington, DC: National Highway Traffic Safety Administration. 


\section{Technical Report Documentation Page}

\begin{tabular}{|c|c|c|}
\hline $\begin{array}{l}\text { 1. Report No. } \\
\text { DOT HS } 812106\end{array}$ & 2. Government Accession No. & 3. Recipient's Catalog No. \\
\hline \multirow{2}{*}{\multicolumn{2}{|c|}{$\begin{array}{l}\text { 4. Title and Subtitle } \\
\text { Evaluation of ISO CRS Envelopes Relative to U.S. Vehicles and Child } \\
\text { Restraint Systems }\end{array}$}} & $\begin{array}{l}\text { 5. Report Date } \\
\text { January } 2015\end{array}$ \\
\hline & & 6. Performing Organization Code \\
\hline $\begin{array}{l}\text { 7. Authors } \\
\text { Hu, Jingwen; Manary, Miriam } \\
\text { Matthew P. }\end{array}$ & A.; Klinich, Kathleen D.; Reed, & $\begin{array}{l}\text { 8. Performing Organization Report No. } \\
\text { UMTRI-2014-17 }\end{array}$ \\
\hline \multirow{2}{*}{\multicolumn{2}{|c|}{$\begin{array}{l}\text { 9. Performing Organization Name and Address } \\
\text { University of Michigan Transportation Research Institute } \\
2901 \text { Baxter Rd. } \\
\text { Ann Arbor, MI } 48109\end{array}$}} & 10. Work Unit No. (TRAIS) \\
\hline & & 11. Contract or Grant No. \\
\hline \multirow{2}{*}{\multicolumn{2}{|c|}{$\begin{array}{l}\text { 12. Sponsoring Agency Name and Address } \\
\text { National Highway Traffic Safety Administration } \\
1200 \text { New Jersey Avenue SE } \\
\text { Washington, DC } 20590\end{array}$}} & $\begin{array}{l}\text { 13. Type of Report and Period Covered } \\
\text { April } 2012 \text { - July } 2013\end{array}$ \\
\hline & & 14. Sponsoring Agency Code \\
\hline
\end{tabular}

15. Supplementary Notes

16. Abstract

The objectives of this study are to use computer simulation to evaluate the ISO 13216-3:2006(E) child restraint system (CRS) envelopes relative to rear seat compartments from vehicles and CRSs in the U.S. market, and to demonstrate whether necessary modifications can be made to introduce such a system into compatibility evaluations between U.S. vehicles and CRSs. Three-dimensional geometry models for 26 vehicles and 16 convertible CRS designs developed previously were used. Geometry models of three forward-facing and three rear-facing CRS envelopes provided by the International Organization for Standardization (ISO) were built in the current study. The virtual fit process closely followed the physical procedures described in the ISO standards. The results showed that the current ISO rear-facing envelopes can provide reasonable classifications for CRSs and vehicles, but the forward-facing envelopes do not represent products currently in the U.S. market. In particular, all of the selected vehicles can accommodate the largest forward-facing CRS envelope, while half of the selected CRSs cannot fit within any forward-facing CRS envelopes. The results also indicate that the rear seat compartment in U.S. vehicles often cannot accommodate a large portion of convertible CRSs in the rear-facing position. The increased demand for vehicle fuel economy and the recommendation to keep children rear-facing longer may lead to smaller cars and larger CRSs, which may increase the potential for fit problems.

17. Key Word

Child restraint system, ISO envelope, Computer model

19. Security Classif. (of this report)
18. Distribution Statement

Document is available to the public from the National Technical Public Service www.ntis.gov

\begin{tabular}{|l|l|l|l|}
\hline 19. Security Classif. (of this report) & 20. Security Classif. (of this page) & $\begin{array}{l}21 . \text { No. of } \\
\text { Pages } \\
42\end{array}$ & 22. Price \\
\hline
\end{tabular}

Form DOT F 1700.7 (8-72) $\quad$ Reproduction of completed page authorized 


\section{Acknowledgments}

This work was funded by the National Highway Traffic Safety Administration under cooperative agreement DTNH22-10-H-00288 with the University of Michigan. The opinions expressed herein are those of the authors and do not necessarily represent those of the funding agencies. 


\section{Table of Contents}

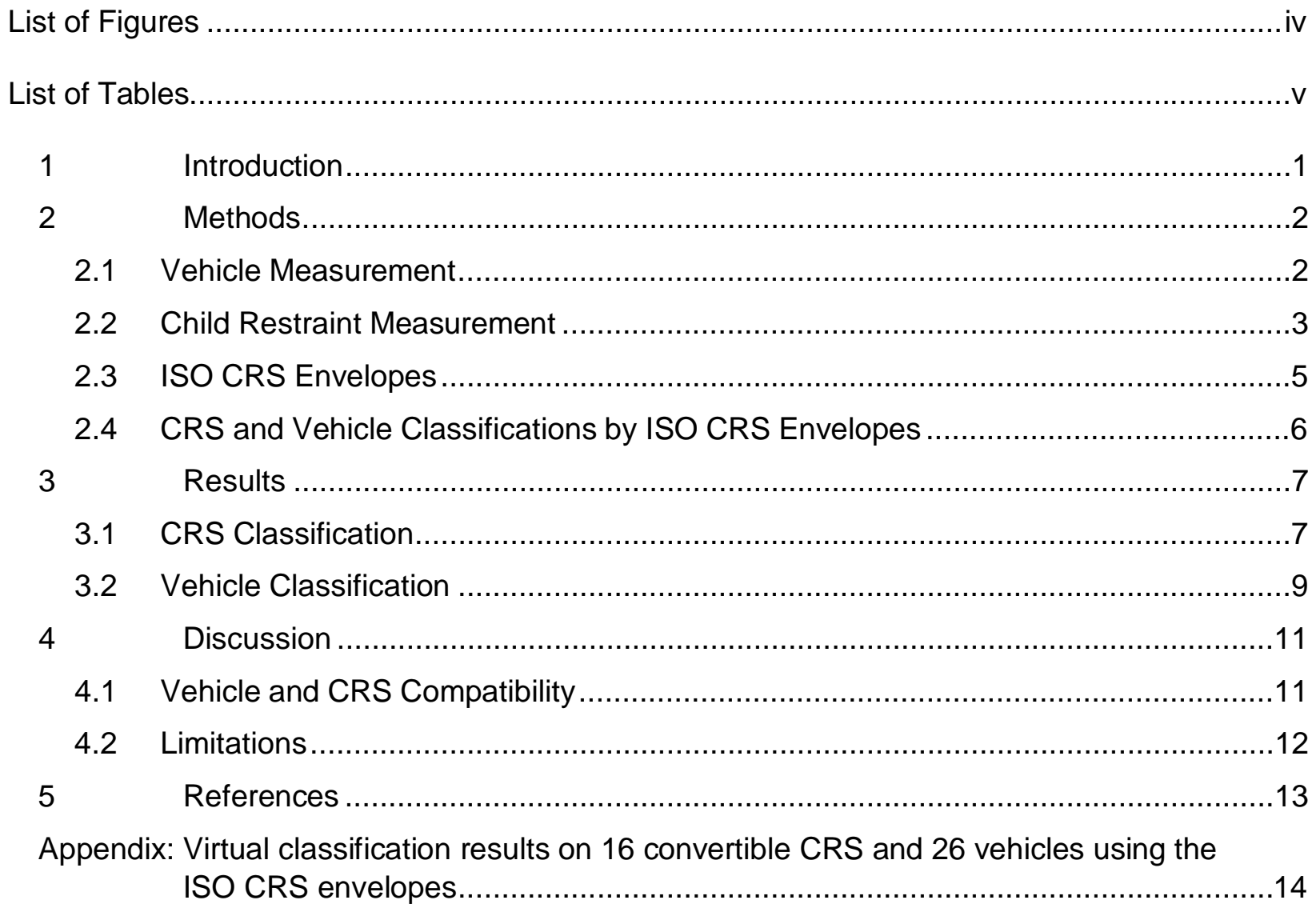




\section{List of Figures}

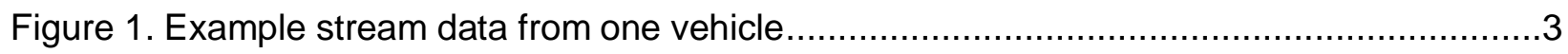

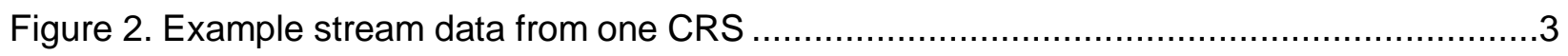

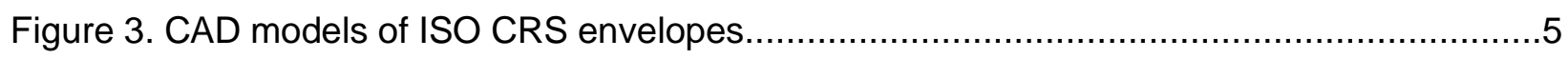

Figure 4. Examples of CRS and vehicle virtual classification ......................................6

Figure 5. Examples of virtual CRS classification results (Results for each of the 16 CRSs are

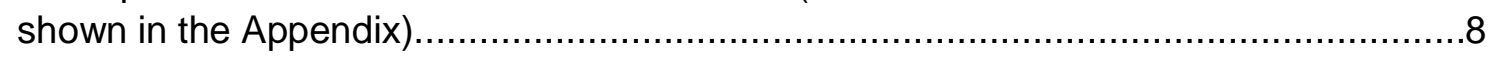

Figure 6. Examples of virtual CRS classification results (Results for each of the 26 vehicles are

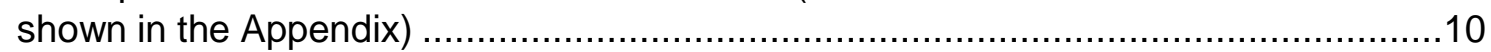




\section{List of Tables}

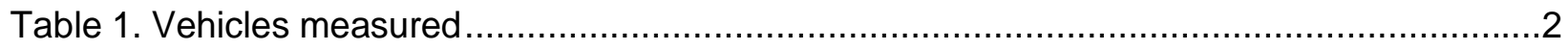

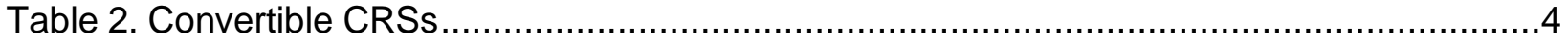

Table 3. ISO Classification of CRSs and vehicles ........................................................

Table 4. Evaluation results for 16 convertible CRSs in boh forward-facing and

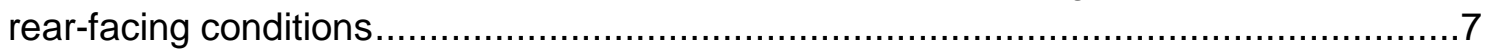

Table 5. Rear seat evaluation results for 26 vehicles by ISO CRS envelopes.........................9 


\section{Introduction}

A common problem encountered by parents or caregivers when selecting and using child restraint systems (CRSs) is that some CRS models are too large to be installed properly in some vehicles. Mandates for increased vehicle fuel economy and consumer demand for more-energyefficient vehicles have increased the number of smaller cars in the new-vehicle fleet. At the same time, CRSs are getting larger. In particular, with the recent emphasis on keeping children rear-facing until they are two years old, many rear-facing CRS designs have increased in size to accommodate larger toddlers. Frequently, these larger CRSs will contact the back of the vehicle seat located in front of them in a way that prohibits achieving the prescribed CRS recline angle, inhibits the positions or recline angle of the vehicle front seat, potentially interferes with vehicle occupant sensing systems in the front seats (if present), and/or is not allowed by the vehicle/CRS instructions for proper use. Moreover, larger CRSs that accommodate larger children forward-facing with a harness system may encounter interference from the more prominent FMVSS No. 202-compliant head restraints in the rear seats.

To date in the United States there has not been an orchestrated attempt to match the size of CRSs with the available interior volume of vehicle rear seats to help inform consumer's purchasing choices and to aid in vehicle and CRS design decisions. Internationally, this issue has been addressed by International Standards Organization (ISO) TC22/SC12/WG1 through the development of ISO 13216-3:2006(E). ISO 13216-3 (ISO 2006) was developed to create a classification system for child restraints and vehicles that helps consumers match CRSs and vehicles that are dimensionally compatible. The standard defines eight envelopes, three for rear-facing CRSs, three for forward-facing CRSs, and two for car beds. Car beds are more commonly used in Europe but are only used in situations of medical necessity in the United States and were therefore outside the scope of the current effort. Envelopes for booster seats were not defined in this ISO document.

A research study on the geometry of second-row, outboard seating positions was previously conducted at the University of Michigan Transportation Research Institute (UMTRI; Reed, EbertHamilton, \& Klinich, 2012). Detailed measurements were made in 26 late-model vehicles, with a focus on small cars and those with prominent second-row head restraints. The driver position was measured in each of the vehicles to enable calculation of expected driver-selected seat positions. Additionally, the 3D geometries of 16 convertible CRSs were also measured in that study. These data enable virtual evaluations of CRSs and vehicles using the ISO CRS envelopes.

The objectives of this study were:

1) to virtually evaluate the ISO CRS envelopes relative to rear seat compartments from 26 U.S. vehicles and 16 U.S. CRSs,

2) to demonstrate whether the ISO CRS envelopes are suitable for the U.S. market, and

3) to identify modifications that might allow introduction of such a system into compatibility evaluations between U.S. vehicles and CRSs. 


\section{Methods}

\subsection{Vehicle Measurement}

In previous UMTRI research, a FARO arm coordinate digitizer (Bronze Model, FARO Technologies, Lake Mary, FL) was used to measure the interior geometry of passenger vehicles. Seat, floor, roof, and pillar surfaces shapes were outlined and then sampled in a grid pattern as shown in Figure 1. The H-point locations for the driver and rear seats were measured using the procedures in SAE J826 with the H-point machine (SAE, 2004). The fore-aft, up-down, and recline adjustment range of the driver seats, as well as the LATCH locations of the rear seats were also measured. The sample of vehicles was selected based on several criteria. The primary emphasis was on small sedans with reasonably accessible second-row seats and vehicles identified as having prominent head restraints. Several SUVs, minivans, and full-size passenger cars were also included. Table 1 lists the 26 vehicles used in the current study.

Table 1. Vehicles measured

\begin{tabular}{|c|c|c|c|c|}
\hline $\begin{array}{c}\text { UMTRI Vehicle } \\
\text { Number }\end{array}$ & Make & Model & Year & Category \\
\hline 65 & Chevrolet & Traverse & 2011 & SUV \\
\hline 66 & Volvo & XC60 & 2010 & SuV† \\
\hline 67 & Ford & Taurus & 2006 & Passenger \\
\hline 68 & Honda & Civic & 2010 & Passenger \\
\hline 69 & Dodge & Caravan & 2010 & Minivan \\
\hline 70 & Ford & Taurus & 2011 & Passenger† \\
\hline 71 & Hyundai & Sonata & 2011 & Passenger† \\
\hline 72 & Toyota & Sienna & 2011 & Minivan† \\
\hline 73 & Chrysler & Dodge Grand Caravan & 2011 & Minivan† \\
\hline 74 & $\mathrm{Kia}$ & Soul & 2011 & Passenger \\
\hline 75 & Nissan & Versa & 2011 & Passengert \\
\hline 76 & Chevrolet & Impala & 2011 & Passenger $\dagger$ \\
\hline 77 & Ford & Explorer & 2011 & SUV† \\
\hline 78 & Mitsubishi & Lancer & 2011 & Passenger† \\
\hline 79 & Mazda & Mazda 3 & 2011 & Passenger \\
\hline 80 & Ford & F-150 & 2011 & Pickup \\
\hline 81 & Chevrolet & Tahoe & 2011 & SUV† \\
\hline 82 & Volkswagen & Eos & 2012 & Passenger* \\
\hline 83 & Audi & A4 & 2004 & Passenger \\
\hline 84 & Ford & Focus & 2004 & Passenger \\
\hline 85 & Hyundai & Accent & 2010 & Passenger \\
\hline 86 & Honda & Fit & 2009 & Passenger \\
\hline 87 & Nissan & Cube & 2011 & Passenger \\
\hline 88 & Ford & Fiesta & 2011 & Passenger \\
\hline 89 & Chevrolet & Aveo & 2011 & Passenger \\
\hline 90 & Toyota & Corolla & 2009 & Passenger \\
\hline
\end{tabular}

*2-door, † Prominent head restraint 


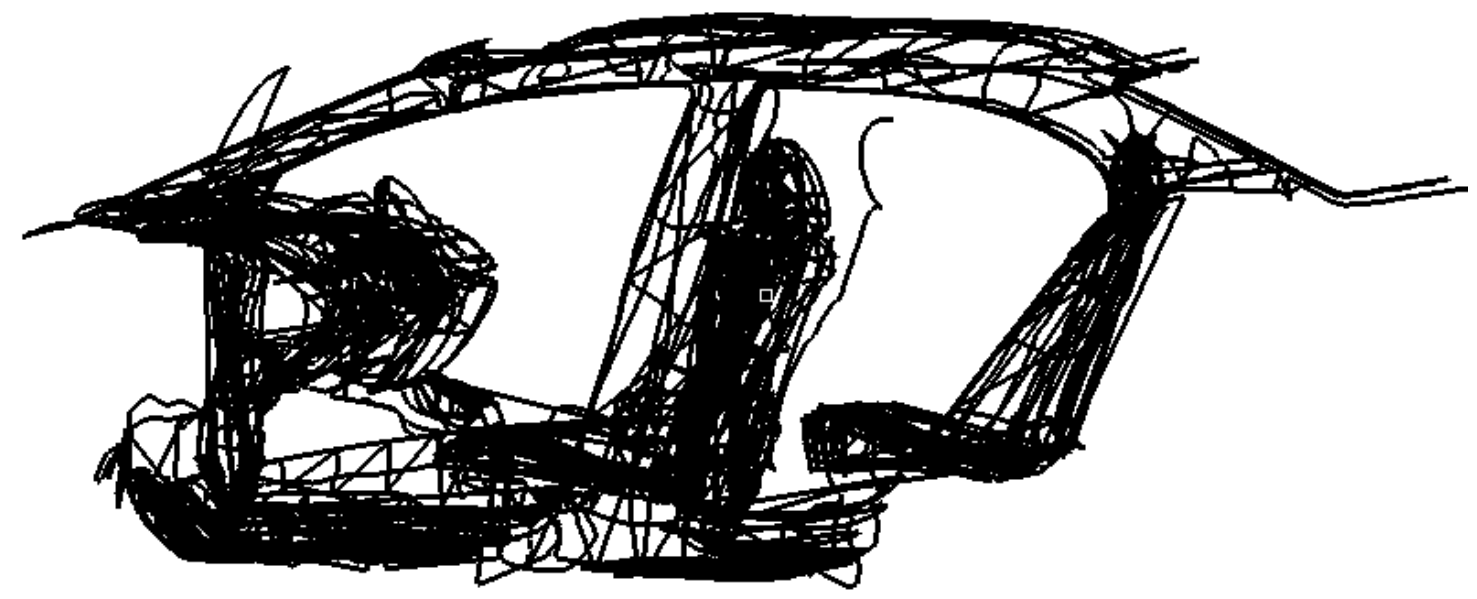

Figure 1. Example stream data from one vehicle

\subsection{Child Restraint Measurement}

A FARO arm coordinate digitizer was used to record the overall size and shape of 16 convertible CRSs purchased in 2009. Figure 2 shows the stream data for one CRS as an example, and Table 2 shows each CRS in the forward-facing harness configuration.

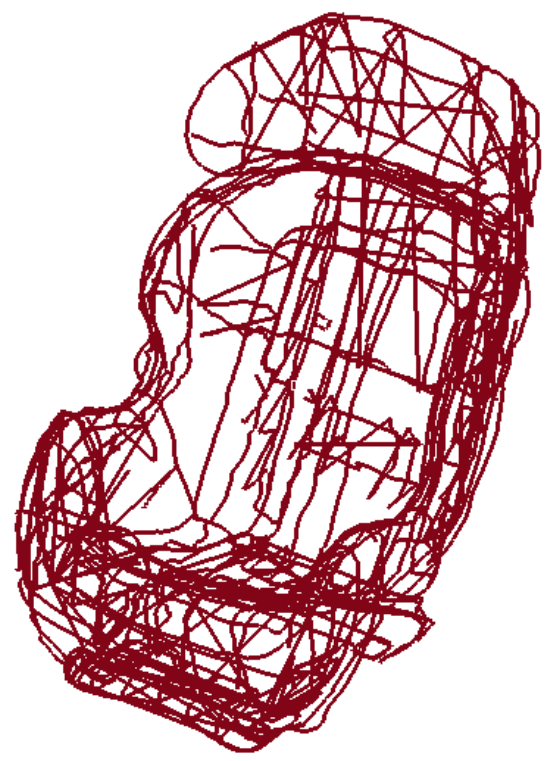

Figure 2. Example stream data from one CRS 
Table 2. Convertible CRSs

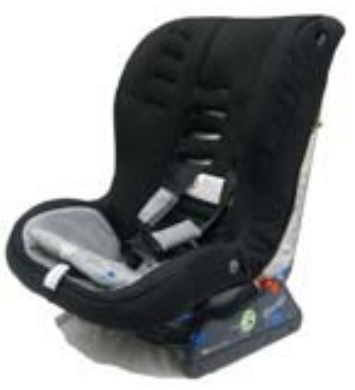

C01 Orbit Baby

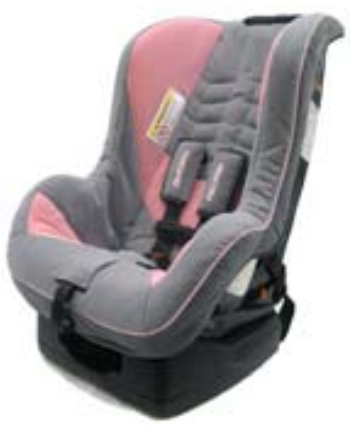

C05 Recaro

Como

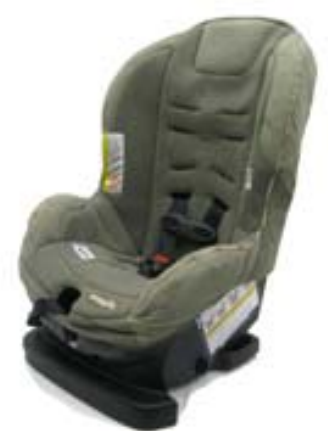

C09 Evenflo

Titan Elite

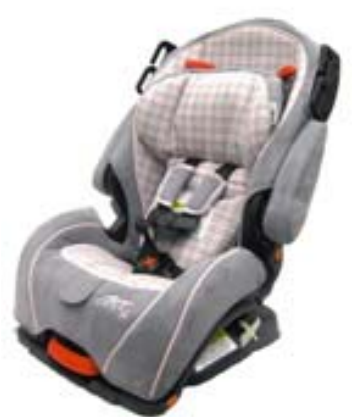

C13 Alpha Omega Elite

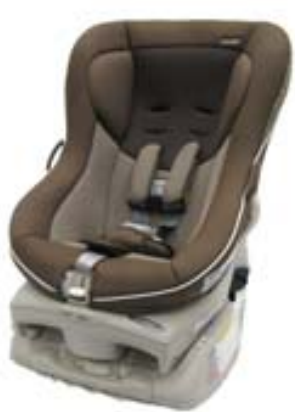

C02 Combi Zeus Turn

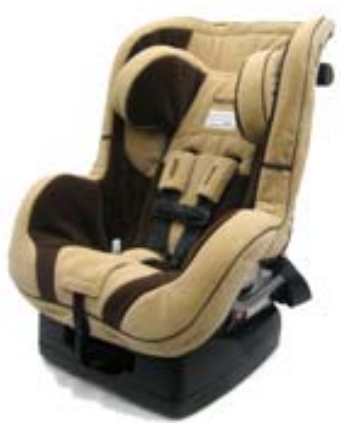

C06 Recaro Signo

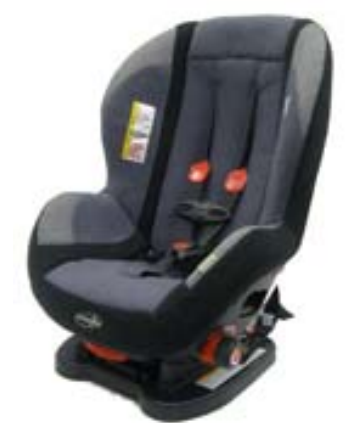

C10 Evenflo Triumph Advance Deluxe

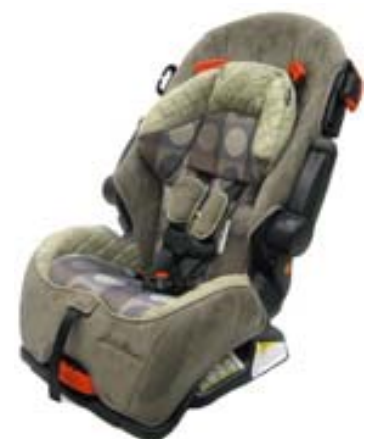

C14 Eddie Bauer

Deluxe 3in1

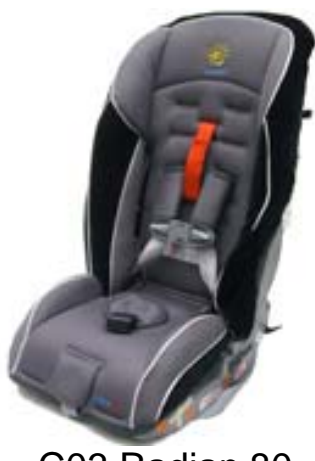

C03 Radian 80

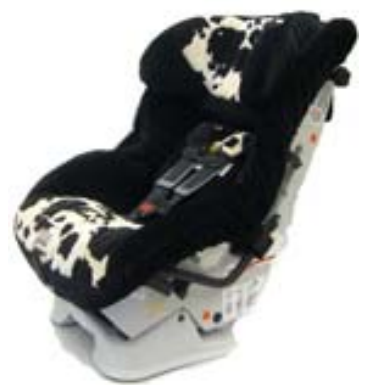

C07 Britax

Boulevard CS

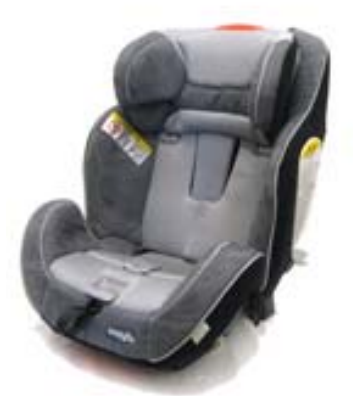

C11 Evenflo Symphony

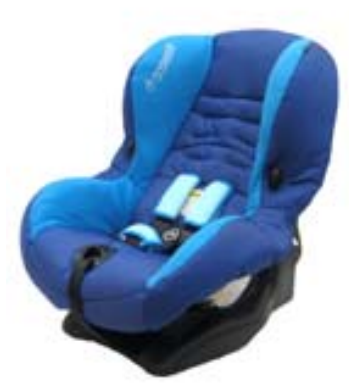

C15 Dorel

Maxi-Cosi Priori

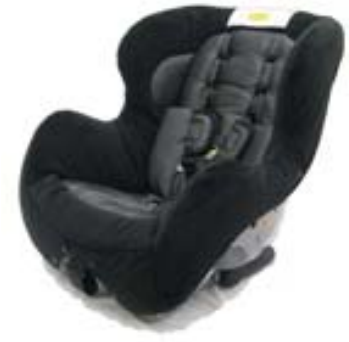

C04 The First Year True Fit
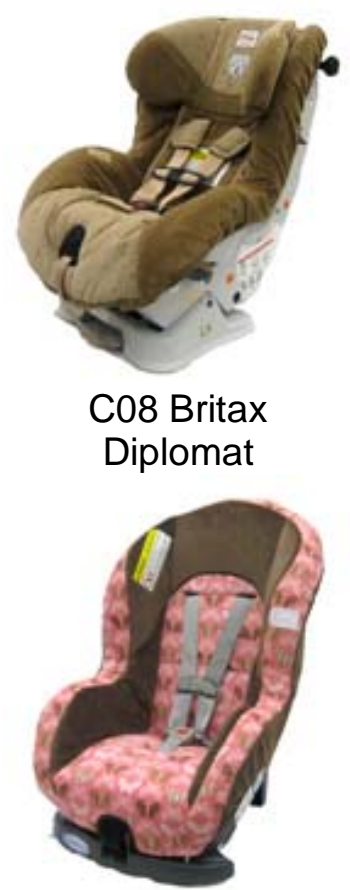

C12 Graco ComfortSport

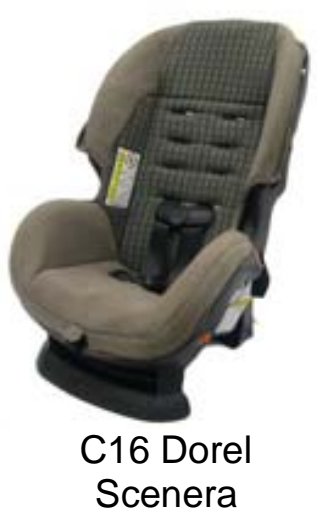




\subsection{ISO CRS Envelopes}

CAD models of six CRS envelopes defined by the ISO standard for forward- and rear-facing CRSs were developed in the current study, and are shown in Figure 3. These models accounted for the dimension errors in the current published standard. The ISO classification system for forward- and rear-facing CRSs, as well as the available space for vehicle seating positions is described in Table 3. Note that if a CRS fits into ISO/R1, it will fit into ISO/R2. If a CRS fits into ISO/R2, it will fit into ISO/R3. However, if a CRS fits into ISO/F2X, it does not necessarily indicate that it will fit into ISO/F3 because of the extended seatback upper part in ISO/F2X. The ISO CRS envelopes all contain a representation of the rigid lower connectors that are required in Europe by the ISOFix regulation. Rigid connectors are allowed but not required in the United States.

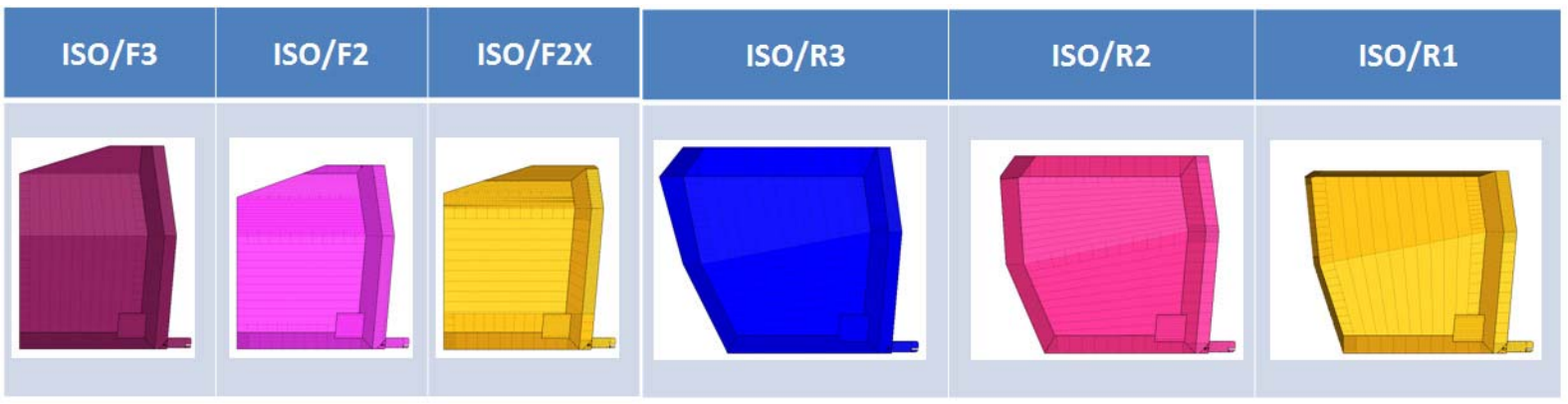

Figure 3. CAD models of ISO CRS envelopes

Table 3. ISO Classification of CRSs and vehicles

\begin{tabular}{lll}
\hline Classification & \multicolumn{1}{c}{ CRS description } & \multicolumn{1}{c}{ Vehicle description } \\
\hline ISO/F3 & $\begin{array}{l}\text { Full-height forward-facing } \\
\text { toddler CRS with height range } \\
\text { from 650-720 mm }\end{array}$ & $\begin{array}{l}\text { The vehicle seating position } \\
\text { accommodates a full-height forward facing } \\
\text { toddler CRS }\end{array}$ \\
\hline ISO/F2 & $\begin{array}{l}\text { Reduced-height forward-facing } \\
\text { toddler CRS (height max 650 } \\
\text { mm) }\end{array}$ & $\begin{array}{l}\text { The vehicle seating position } \\
\text { accommodates a reduced-height forward } \\
\text { facing toddler CRS }\end{array}$ \\
\hline ISO/F2X & $\begin{array}{l}\text { Reduced-height forward-facing } \\
\text { toddler CRS (height max 650 } \\
\text { mm) having reduced contour in } \\
\text { the upper part (to allow fitting in } \\
\text { low-roof cars), and an extended } \\
\text { seatback upper part. }\end{array}$ & $\begin{array}{l}\text { The vehicle seating position } \\
\text { accommodates a reduced-height forward- } \\
\text { fapper part (to allow fitting in low-roof cars), } \\
\text { and an extended seatback upper part }\end{array}$ \\
& $\begin{array}{l}\text { Full-size rear-facing toddler } \\
\text { CRS }\end{array}$ & $\begin{array}{l}\text { The vehicle seating position } \\
\text { accommodates a full-size rear-facing } \\
\text { toddler CRS }\end{array}$ \\
\hline ISO/R3 & $\begin{array}{l}\text { The vehicle seating position } \\
\text { accommodates a reduced-size rear-facing } \\
\text { toddler CRS }\end{array}$ \\
\hline ISO/R2 & toddler CRS & $\begin{array}{l}\text { The vehicle seating position } \\
\text { accommodates a rear-facing infant CRS }\end{array}$ \\
\hline ISO/R1 & Rear-facing infant CRS & \\
\hline
\end{tabular}




\subsection{CRS and Vehicle Classifications by ISO CRS Envelopes}

In this study, the procedure to classify CRS and vehicles using the ISO CRS envelopes closely followed the ISO standard. Both forward-facing and rear-facing conditions for each convertible CRS were evaluated using the relevant CRS envelopes. The rear seating position behind the driver seat was evaluated for each vehicle.

When verifying whether a CRS fit within a particular CRS envelope, the bottom surface of the CRS was first aligned with the bottom of the envelope. Then the center of the CRS was adjusted laterally and in the fore-aft direction to best fit the envelope. Since few U.S. CRSs are equipped with rigid lower attachments, no effort was made to adjust a particular CRS so that the lower connectors on the CRS aligned with the lower connectors on the envelope.

When checking a CRS envelope for a rear seating position, the rear vehicle seat was adjusted longitudinally to its rearmost and lowest position if possible. At the same time, the driver seat was adjusted to the mid-position longitudinally and vertically, and the seat back was adjusted to the angle corresponding to a torso angle of $23^{\circ}$ based on the $\mathrm{H}$-point machine measurement (Manary, Reed, Flanagan \& Schneider, 1998). The left connector on the CRS envelope was virtually attached to the left lower anchor for the seating position. During the virtual classification process, the CRS envelopes were adjusted within a pitch angle of $15^{\circ} \pm 5^{\circ}$ to match the centerline of the seat bottom cushion and seat back contours. Examples of CRS and vehicle rear-seat virtual classification using the ISO CRS envelopes are shown in Figure 4.
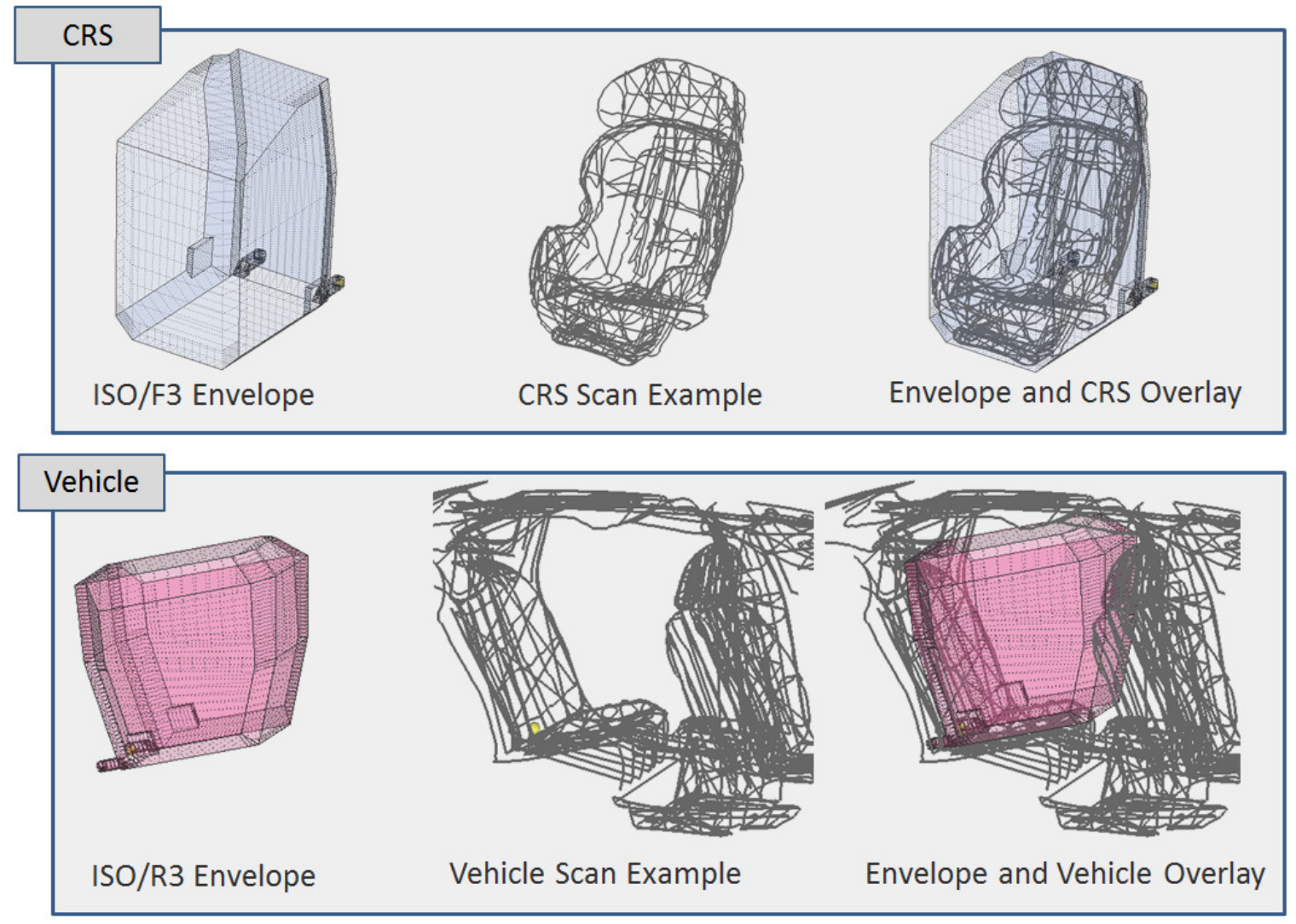

Figure 4. Examples of CRS and vehicle virtual classification 


\section{Results}

\subsection{CRS Classification}

The results of CRS classification by the ISO CRS envelopes are shown in Table 4, and two examples of the process of virtual classification are shown in Figure 5.

When evaluating the 16 convertible CRSs forward-facing, 5 CRSs were classified as ISO/F2 and ISO/F2X (reduced-height), 3 were classified as ISO/F3 (full-height), and 8 could not fit within any of the ISO forward-facing envelopes. For each of these $8 \mathrm{CRSs}$, the top of the CRS protruded beyond the rear-top corner of the CRS envelopes, indicating that rear seat headrestto-CRS interference could be a potential concern. These results indicated that CRS designs in the U.S. market are much larger than the volumes defined by the ISO standards. In addition, the 2 reduced-height forward-facing CRS envelopes (ISO/F2 and ISO/F2X) do not provide enough differentiation to separate designs among the 16 CRS in this study.

When evaluating the 16 convertible CRSs rear-facing, 2 of them were classified as ISO/R1 (smallest), 4 were classified as ISO/R2 (medium), 9 were classified as ISO/R3 (largest), and 1 could not fit within any of the ISO rear-facing envelopes. These results suggested that the rearfacing ISO envelopes work reasonably well for the CRS designs in the U.S. market, although most CRSs are toward the large end.

Table 4. Evaluation results for 16 convertible CRSs in both forward-facing and rear-facing conditions

\begin{tabular}{l|c|c|c|c|c|c}
\hline \multicolumn{1}{c|}{ CRS } & ISO/F3 & ISO/F2 & ISO/F2X & ISO/R3 & ISO/R2 & ISO/R1 \\
\hline C01 Orbit Baby & $\mathrm{N}$ & $\mathrm{N}$ & $\mathrm{N}$ & $\mathrm{Y}$ & $\mathrm{N}$ & $\mathrm{N}$ \\
C02 Combi Zeus Turn & $\mathrm{Y}$ & $\mathrm{N}$ & $\mathrm{N}$ & $\mathrm{Y}$ & $\mathrm{N}$ & $\mathrm{N}$ \\
C03 Radian 80 & $\mathrm{Y}$ & $\mathrm{N}$ & $\mathrm{N}$ & $\mathrm{N}$ & $\mathrm{N}$ & $\mathrm{N}$ \\
C04 The First Years True Fit & $\mathrm{N}$ & $\mathrm{N}$ & $\mathrm{N}$ & $\mathrm{Y}$ & $\mathrm{Y}$ & $\mathrm{Y}$ \\
C05 Recaro Como & $\mathrm{N}$ & $\mathrm{N}$ & $\mathrm{N}$ & $\mathrm{Y}$ & $\mathrm{Y}$ & $\mathrm{N}$ \\
C06 Recaro Signo & $\mathrm{N}$ & $\mathrm{N}$ & $\mathrm{N}$ & $\mathrm{Y}$ & $\mathrm{Y}$ & $\mathrm{N}$ \\
C07 Britax Boulevard CS & $\mathrm{N}$ & $\mathrm{N}$ & $\mathrm{N}$ & $\mathrm{Y}$ & $\mathrm{N}$ & $\mathrm{N}$ \\
C08 Britax Diplomat & $\mathrm{N}$ & $\mathrm{N}$ & $\mathrm{N}$ & $\mathrm{Y}$ & $\mathrm{Y}$ & $\mathrm{Y}$ \\
C09 Evenflo Titan Elite & $\mathrm{Y}$ & $\mathrm{Y}$ & $\mathrm{Y}$ & $\mathrm{Y}$ & $\mathrm{N}$ & $\mathrm{N}$ \\
C10 Evenflo Triumph Advance & $\mathrm{Y}$ & $\mathrm{N}$ & $\mathrm{N}$ & $\mathrm{Y}$ & $\mathrm{Y}$ & $\mathrm{N}$ \\
$\quad$ Deluxe & $\mathrm{N}$ & $\mathrm{N}$ & $\mathrm{N}$ & $\mathrm{Y}$ & $\mathrm{N}$ & $\mathrm{N}$ \\
C11 Evenflo Symphony & $\mathrm{Y}$ & $\mathrm{Y}$ & $\mathrm{Y}$ & $\mathrm{Y}$ & $\mathrm{N}$ & $\mathrm{N}$ \\
C12 Graco ComfortSport & $\mathrm{Y}$ & $\mathrm{Y}$ & $\mathrm{Y}$ & $\mathrm{Y}$ & $\mathrm{Y}$ & $\mathrm{N}$ \\
C13 Alpha Omega Elite & $\mathrm{N}$ & $\mathrm{N}$ & $\mathrm{N}$ & $\mathrm{Y}$ & $\mathrm{N}$ & $\mathrm{N}$ \\
C14 Eddie Bauer Deluxe 3in1 & $\mathrm{Y}$ & $\mathrm{Y}$ & $\mathrm{Y}$ & $\mathrm{Y}$ & $\mathrm{N}$ & $\mathrm{N}$ \\
C15 Dorel Maxi-Cosi Priori & $\mathrm{Y}$ & $\mathrm{Y}$ & $\mathrm{Y}$ & $\mathrm{Y}$ & $\mathrm{N}$ & $\mathrm{N}$ \\
C16 Dorel Scenera & 3 & & & 9 & 4 & 2 \\
\hline Number of CRSs in each & & & & \\
category & & &
\end{tabular}

Note: The final ISO categories are highlighted in bold. The smallest ISO envelop that a CRS can fit within is considered to be the final ISO category for that CRS. 

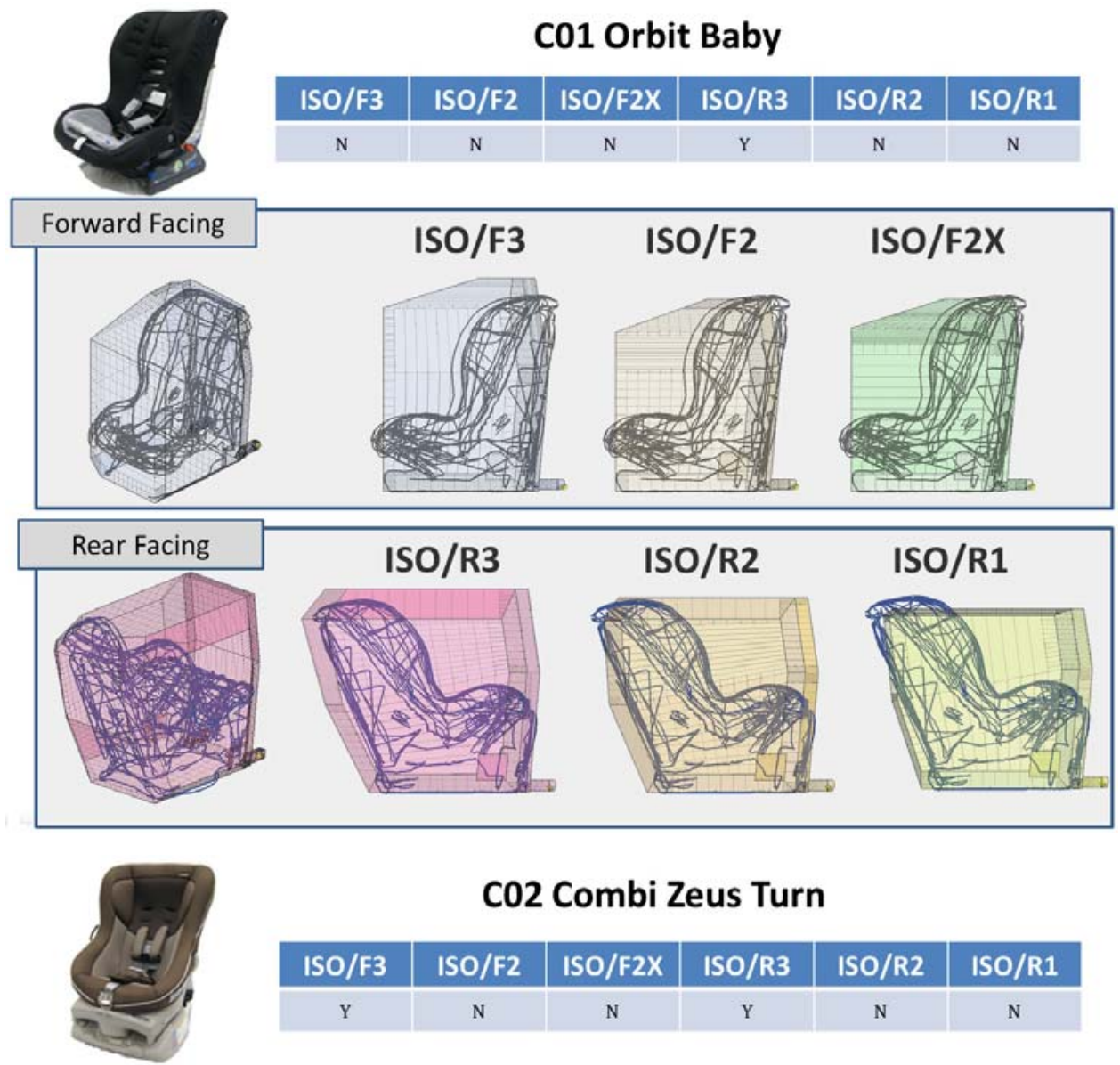

C02 Combi Zeus Turn

\begin{tabular}{|c|c|c|c|c|c|}
\hline ISO/F3 & ISO/F2 & ISO/F2X & ISO/R3 & ISO/R2 & ISO/R1 \\
\hline Y & N & N & Y & N & N \\
\hline
\end{tabular}
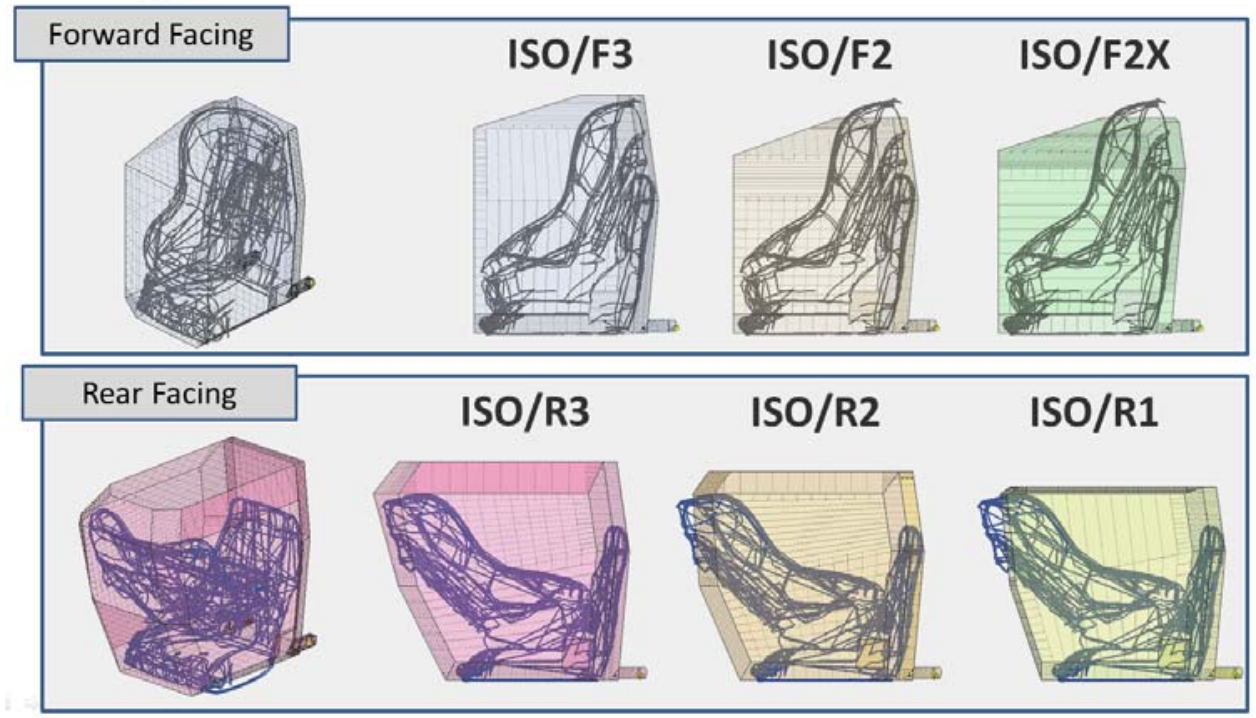

Figure 5. Examples of virtual CRS classification results (Results for each of the 16 CRSs are shown in the Appendix) 


\subsection{Vehicle Classification}

The results of vehicle classification by the ISO CRS envelopes are shown in Table 5, and two examples of the virtual classification are shown in Figure 6. All 26 vehicles evaluated could accommodate the largest forward-facing CRS envelope (ISO/F3) without interference with the vehicle interior, such as the rear seat head restraint or the back of the front seat. However, only 11 vehicles could accommodate the largest rear-facing CRS envelope (ISO/R3), 4 could accommodate the mid-size rear-facing envelope (ISO/R2), 9 could accommodate the smallest rear-facing envelope (ISO/R1), and 2 vehicles could not accommodate any of the rear-facing envelopes. During the virtual evaluation process, no interference between the forward-facing CRS envelopes and the rear seat head restraints was found. The interferences only occurred between the envelopes and the back of the front seats.

Table 5. Rear seat evaluation results for 26 vehicles by ISO CRS envelopes

\begin{tabular}{|c|c|c|c|c|c|c|}
\hline Vehicle & ISO/F3 & ISO/F2 & ISO/F2X & ISO/R3 & ISO/R2 & ISO/R1 \\
\hline 65 SUV raverse11 & $\mathrm{Y}$ & $\mathrm{Y}$ & $\mathrm{Y}$ & $\mathrm{Y}$ & $\mathrm{Y}$ & $\mathrm{Y}$ \\
\hline 66 SUV XC6008 & Y & Y & $\mathrm{Y}$ & $\mathrm{Y}$ & $\mathrm{Y}$ & $\mathrm{Y}$ \\
\hline 67 PasTaurus06 & Y & Y & Y & $Y$ & Y & Y \\
\hline 68 PasCivic10 & Y & Y & Y & N & Y & Y \\
\hline 69 MnvCaravan10 & Y & Y & Y & $\mathrm{Y}$ & $\mathrm{Y}$ & $\mathrm{Y}$ \\
\hline 70 PasTaurus11 & Y & Y & Y & $Y$ & Y & Y \\
\hline 71 PasSonata11 & Y & Y & $\mathrm{Y}$ & $\mathrm{Y}$ & $\mathrm{Y}$ & $\mathrm{Y}$ \\
\hline 72 MnvSienna11 & Y & Y & Y & $\mathrm{Y}$ & $\mathrm{Y}$ & $\mathrm{Y}$ \\
\hline 73 MnvGrandCaravan11 & Y & Y & Y & Y & Y & Y \\
\hline 74 PasSoul11 & Y & Y & Y & $N$ & Y & Y \\
\hline 75 PasVersa11 & Y & Y & Y & $Y$ & Y & Y \\
\hline 76 Paslmpala11 & Y & Y & Y & $\mathrm{N}$ & $N$ & $\mathrm{Y}$ \\
\hline 77 SUV Explorer11 & Y & Y & Y & $\mathrm{N}$ & $Y$ & Y \\
\hline 78 PasLancer11 & Y & Y & $Y$ & $\mathrm{~N}$ & $Y$ & Y \\
\hline 79 PasMazda311 & Y & Y & $\mathrm{Y}$ & $\mathrm{N}$ & $N$ & Y \\
\hline 80 TrkF15011 & Y & $\mathrm{Y}$ & Y & $Y$ & Y & Y \\
\hline 81 SUVTahoe11 & Y & Y & $\mathrm{Y}$ & $Y$ & $\mathrm{Y}$ & Y \\
\hline 82 PasEos12 & Y & $\mathrm{Y}$ & $\mathrm{Y}$ & $\mathrm{N}$ & $N$ & $\mathrm{~N}$ \\
\hline 83 PasA404 & Y & Y & $Y$ & $\mathrm{~N}$ & $\mathrm{~N}$ & Y \\
\hline 84 PasFocus04 & $Y$ & $\mathrm{Y}$ & $\mathrm{Y}$ & $N$ & $N$ & $Y$ \\
\hline 85 PasAccent10 & Y & $\mathrm{Y}$ & $\mathrm{Y}$ & $\mathrm{N}$ & $\mathrm{N}$ & Y \\
\hline 86 PasFit09 & Y & Y & Y & $\mathrm{N}$ & $N$ & $\mathrm{Y}$ \\
\hline 87 PasCube11 & Y & Y & Y & $\mathrm{N}$ & $\mathrm{N}$ & $Y$ \\
\hline 88 PasFiesta11 & $Y$ & Y & $\mathrm{Y}$ & $\mathrm{N}$ & $\mathrm{N}$ & $N$ \\
\hline 89 PasAveo11 & Y & $\mathrm{Y}$ & $\mathrm{Y}$ & $N$ & $\mathrm{~N}$ & $Y$ \\
\hline 90 PasCorolla09 & Y & $\mathrm{Y}$ & $\mathrm{Y}$ & $\mathrm{N}$ & $\mathrm{N}$ & Y \\
\hline $\begin{array}{l}\text { Number of vehicles in } \\
\text { each category }\end{array}$ & 26 & & & 11 & 4 & 9 \\
\hline
\end{tabular}

Note: The final ISO categories are highlighted in bold. The largest ISO envelope that a vehicle can accommodate is considered to be the final ISO category for that vehicle. 

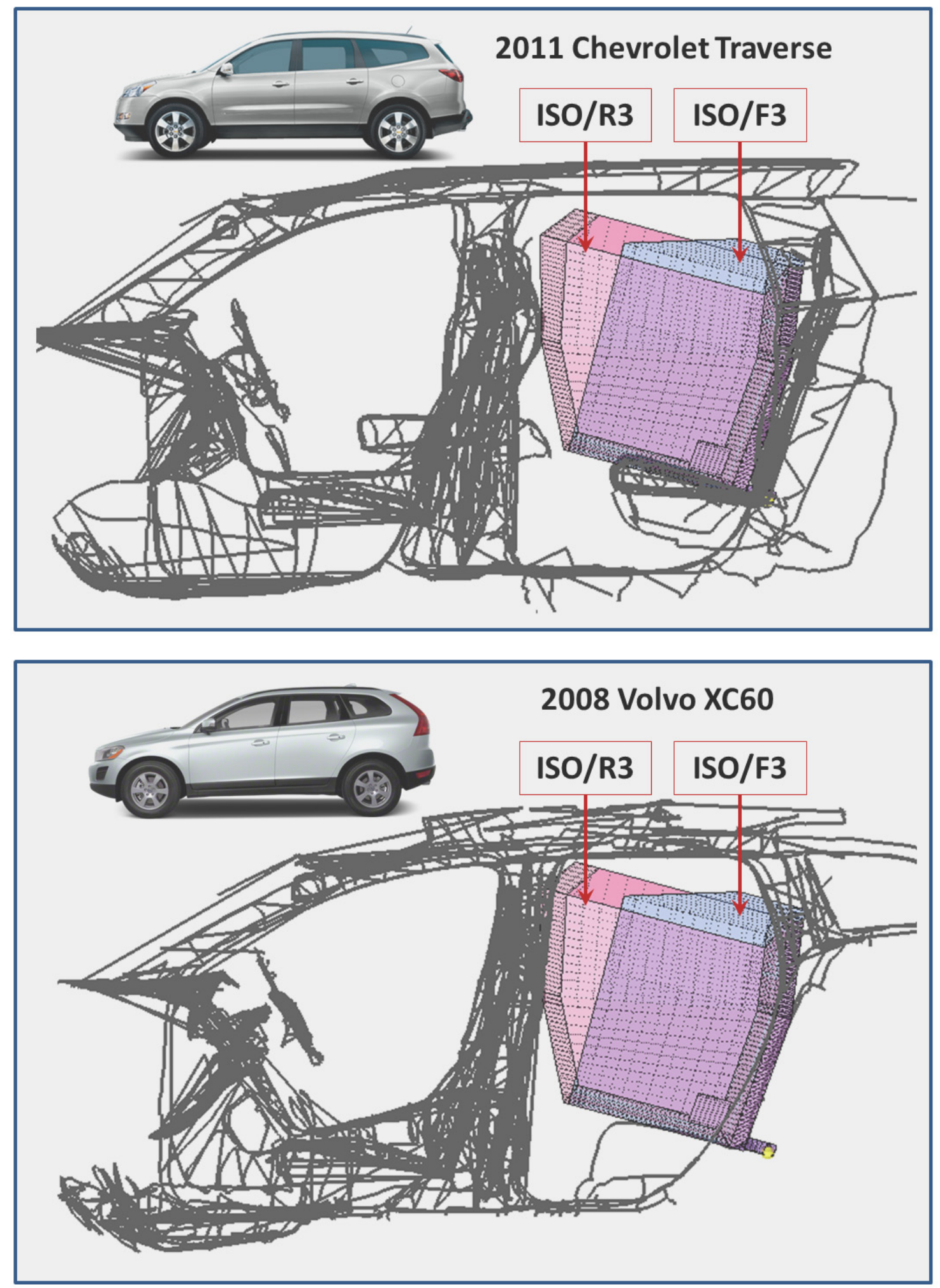

Figure 6. Examples of virtual CRS classification results (Results for each of the 26 vehicles are shown in the Appendix) 


\section{Discussion}

\subsection{Vehicle and CRS Compatibility}

In this study, the ISO CRS envelopes were virtually evaluated relative to 16 U.S. CRSs and the rear seat compartments from 26 U.S. vehicles. The results showed that all of the selected vehicles could accommodate the largest forward-facing CRS envelope at the second-row seat location behind the driver seat. In contrast, half of the selected CRSs could not fit within any of the forward-facing ISO CRS envelopes, mainly due to protrusion at the rear-top corner of the envelope. These results suggested potential contacts between the forward-facing CRSs and the vehicle head restraints in the U.S. market, which may affect the proper installation of the CRSs. This suggests that, in order to introduce CRS envelopes in the United States to improve child restraint and vehicle compatibility, either the largest forward-facing ISO envelope would need to be modified to fit the forward-facing CRSs available in the United States, or U.S. forward-facing CRSs would need to be redesigned to fit within the largest forward-facing ISO envelope.

When using ISO rear-facing CRS envelopes for classification, the selected vehicles and CRSs were distributed reasonably well in the three categories defined by the ISO envelopes, and only one vehicle interior and one CRS were not able to fit any envelopes. This result indicated that, in general, the ISO rear-facing envelopes work well for the vehicles and CRSs in the U.S. market. However, the majority (10/16) of the U.S. CRSs can only fit, or cannot fit, within the largest ISO rear-facing envelope, while less than half $(11 / 26)$ of the U.S. vehicles can accommodate the largest ISO rear-facing envelope. This result indicated that a large portion of rear-facing convertible CRSs cannot be accommodated behind the driver seat in many vehicles. The increased demand for vehicle fuel economy and the recommendation for keeping children rearfacing longer will likely lead to an increase in the number of small cars and larger CRSs, which will further exacerbate the problem for vehicles to accommodate rear-facing CRSs in the future. One of the motivations for the current study was to determine whether current rear seats are sufficiently large enough to install a rear-facing child restraint that can accommodate children weighing more than $22 \mathrm{lbs}$. The results demonstrate that all but one vehicle can accommodate at least one of the ISO rear-facing envelopes that include products that can be used rear-facing up to $30 \mathrm{lbs}$. This indicates that most vehicles can be used to install a rear-facing child restraint with a weight limit of $30 \mathrm{lbs}$, even if they can't be used with all rear-facing child restraints designed to restrain larger children. However, it should be noted that this conclusion is based on an assessment of the seating position behind the driver with the driver seat in the mid-track position.

The virtual classifications indicated that contact between the forward-facing CRSs and the head restraints in the rear seats as well as that between the rear-facing CRSs and the back of the front seats is a main concern regarding the compatibility between the vehicles and the CRSs. Therefore, modification of the current ISO forward-facing CRS envelopes will likely to necessary to ensure they are useful for the U.S. market. Furthermore, the ISO envelopes only address whether the space is acceptable when a CRS is in place on the vehicle seat. They do not cover potential difficulties in maneuvering the CRS to the vehicle seating position. The current ISO standards only provide location-by-location evaluation for vehicles, and do not address the spaces when multiple CRSs are used in a single vehicle. Further improvements may be necessary to evaluate the CRS fit in a more realistic manner. Nevertheless, the ISO envelope 
concept would provide valuable information to the consumers looking to choose a CRS that fits in their vehicles.

\subsection{Limitations}

The simulated CRS envelope fitting procedure has not been validated. In particular, the model did not simulate the seat cushion deformation while positioning an ISO envelope onto the seat. In this study, the envelope was positioned such that the bottom fits the seat cushion contour with constraints at the LATCH location. In any given vehicle, the installed ISO envelope position is likely to be somewhat different from the simulated position.

In addition, the influence of driver seat position and seat back angle on CRS installation was not considered. In the ISO standards the seat back angle can be adjusted, but not to a more upright angle than that corresponding to a torso angle of $15^{\circ}$ measured by the $\mathrm{H}$-point machine. The torso angle $\left(23^{\circ}\right)$ used in the current study represents the typical driving posture, which may lead to an underestimation of rear-seat space compared with using a more upright seat angle based on ISO recommendations.

Because ISOFix requires child restraints to have rigid lower connectors at a specific location, the ISO CRS envelopes also have a rigid lower connector that corresponds well to the locations of the lower connectors on the child restraints. Because most child restraints in the United States use flexible lower connectors, however, the path of the connector from the child restraint to the vehicle lower anchor and the overall position of the CRS relative to the vehicle interior can vary more widely in the United States compared to Europe. If the ISO envelopes were adapted for use in the United States, it is possible that a vehicle that can accommodate an ISO envelope with rigid lower connectors could still have problems achieving good fit with CRSs that fit within the envelope, since the path of the LATCH strap on the CRS could affect the installation orientation. 


\section{References}

International Organization of Standards. (2006). Road vehicles - Anchorages in vehicles and attachments to anchorages for child restraint systems - Part 3: Classification of child restraint dimensions and space in vehicle. ISO 13216-3:2006(E). Geneva: Author.

Manary, M. A., Reed, M. P., Flanagan, C. A. C., \& Schneider, L. W. (1998). ATD positioning based on driver posture and position. (SAE Technical Paper Series No. 983163). Proceedings of the 42nd Stapp Car Crash Conference, Tempe, AZ, Nov. 2-4, 1998. Available at http://mreed.umtri.umich.edu/mreed/pubs/Manary_19983163.pdf

Reed, M. P., Ebert-Hamilton, S. M., \& Klinich, K. D. (2014, August). Characterizing vehicle rear compartment geometry for child restraint applications. (Report No. DOT HS 812 057). Washington, DC: National Highway Traffic Safety Administration. Available at www.nhtsagov/DOT/NHTSA/NVS/Crashworthiness/Child\%20Safety\%20 Crashworthiness\%20Research/812057V ehicleRearCompartmentGeometryChildRestraint Applications.pdf. 
Appendix: Virtual classification results on 16 convertible CRS and 26 vehicles using the ISO CRS envelopes
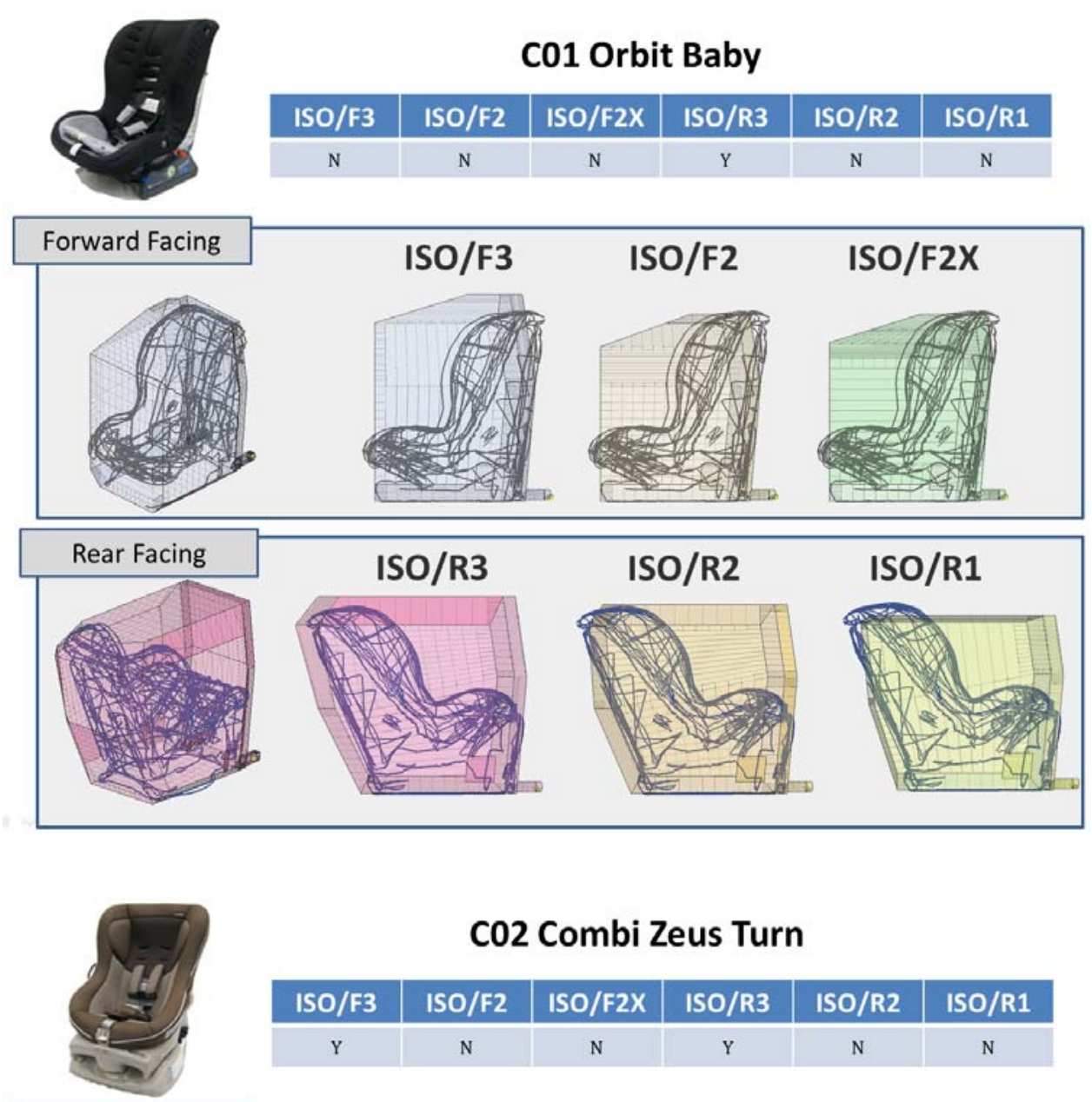

\section{C02 Combi Zeus Turn}

\begin{tabular}{|c|c|c|c|c|c|}
\hline ISO/F3 & ISO/F2 & ISO/F2X & ISO/R3 & ISO/R2 & ISO/R1 \\
\hline Y & N & N & Y & N & N \\
\hline
\end{tabular}

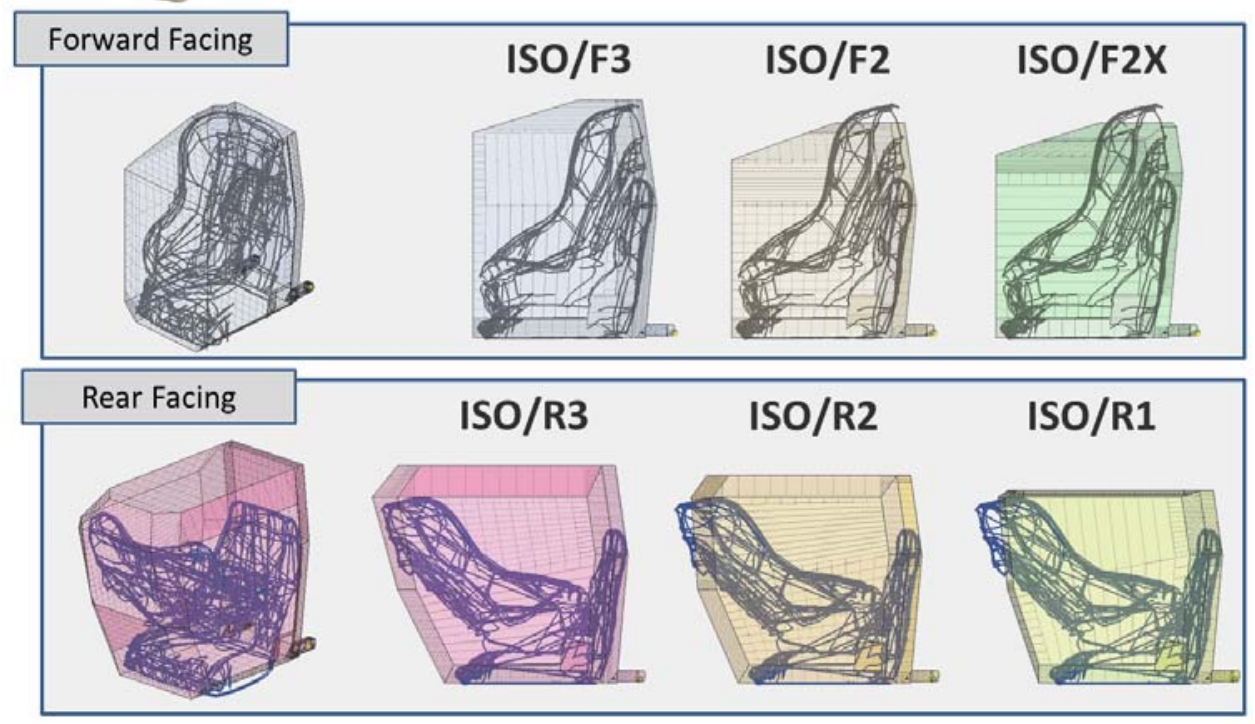



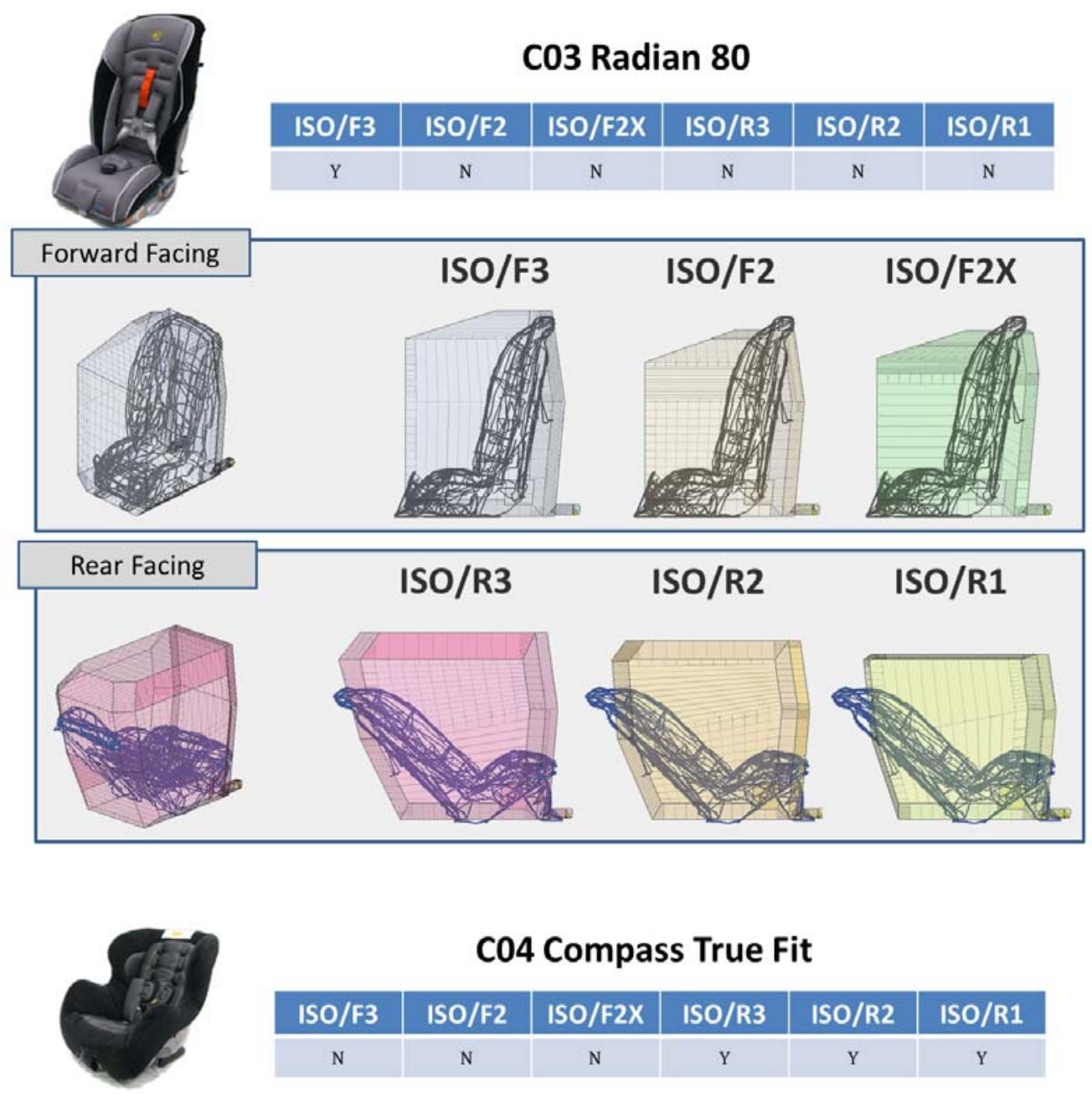

\section{C04 Compass True Fit}

\begin{tabular}{|c|c|c|c|c|c|}
\hline ISO/F3 & ISO/F2 & ISO/F2X & ISO/R3 & ISO/R2 & ISO/R1 \\
\hline N & N & N & Y & Y & Y \\
\hline
\end{tabular}
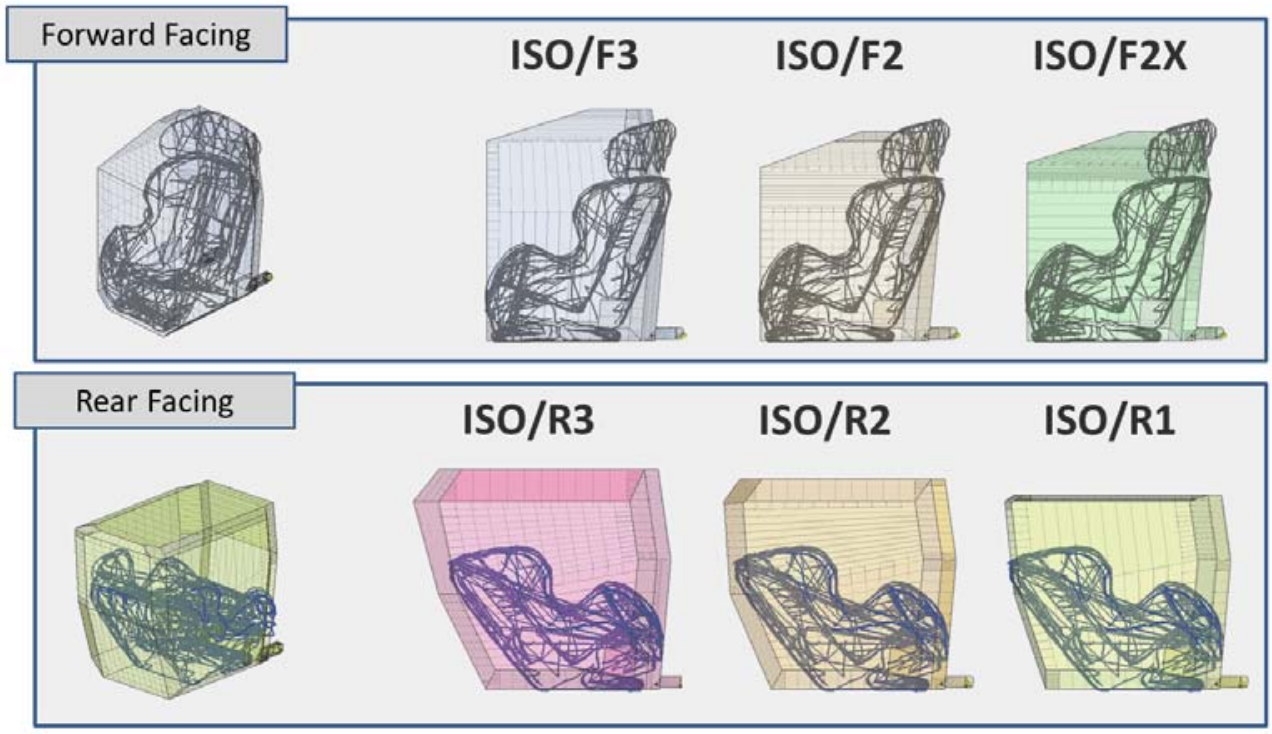

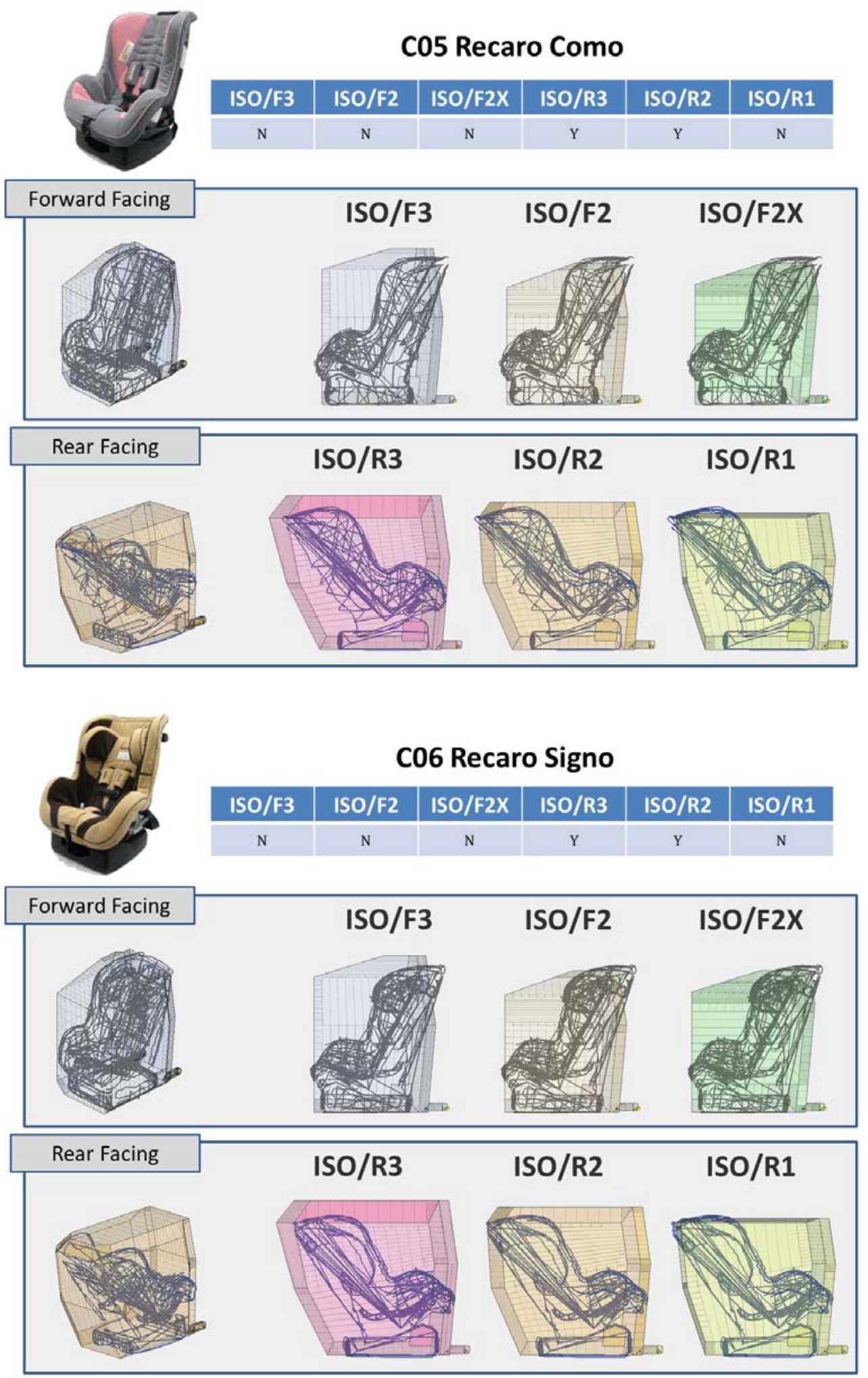


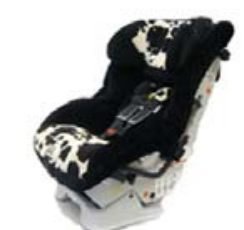

\section{C07 Britax Boulevard CS}

\begin{tabular}{|c|c|c|c|c|c|}
\hline ISO/F3 & ISO/F2 & ISO/F2X & ISO/R3 & ISO/R2 & ISO/R1 \\
\hline N & N & N & Y & N & N \\
\hline
\end{tabular}
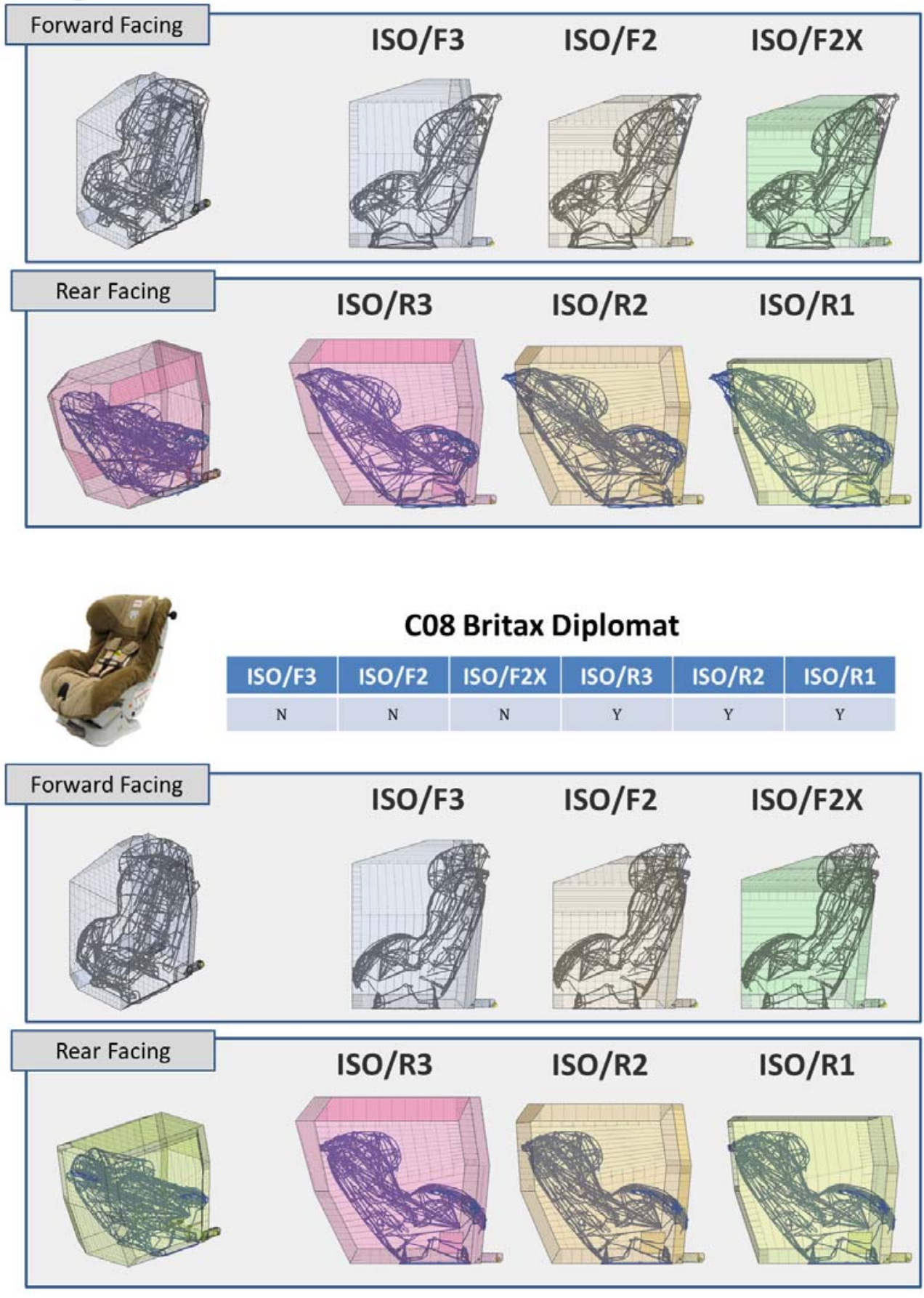


\section{C09 Evenflo Titan Elite}

\section{\begin{tabular}{l|l|l|l|l|l|} 
ISO/F3 & ISO/F2 & ISO/F2X & ISO/R3 & ISO/R2 & ISO/R1
\end{tabular}}

\begin{tabular}{|l|l|l|l|l|l|}
\hline $\mathrm{Y}$ & $\mathrm{Y}$ & $\mathrm{Y}$ & $\mathrm{N}$ & $\mathrm{N}$ \\
\hline
\end{tabular}
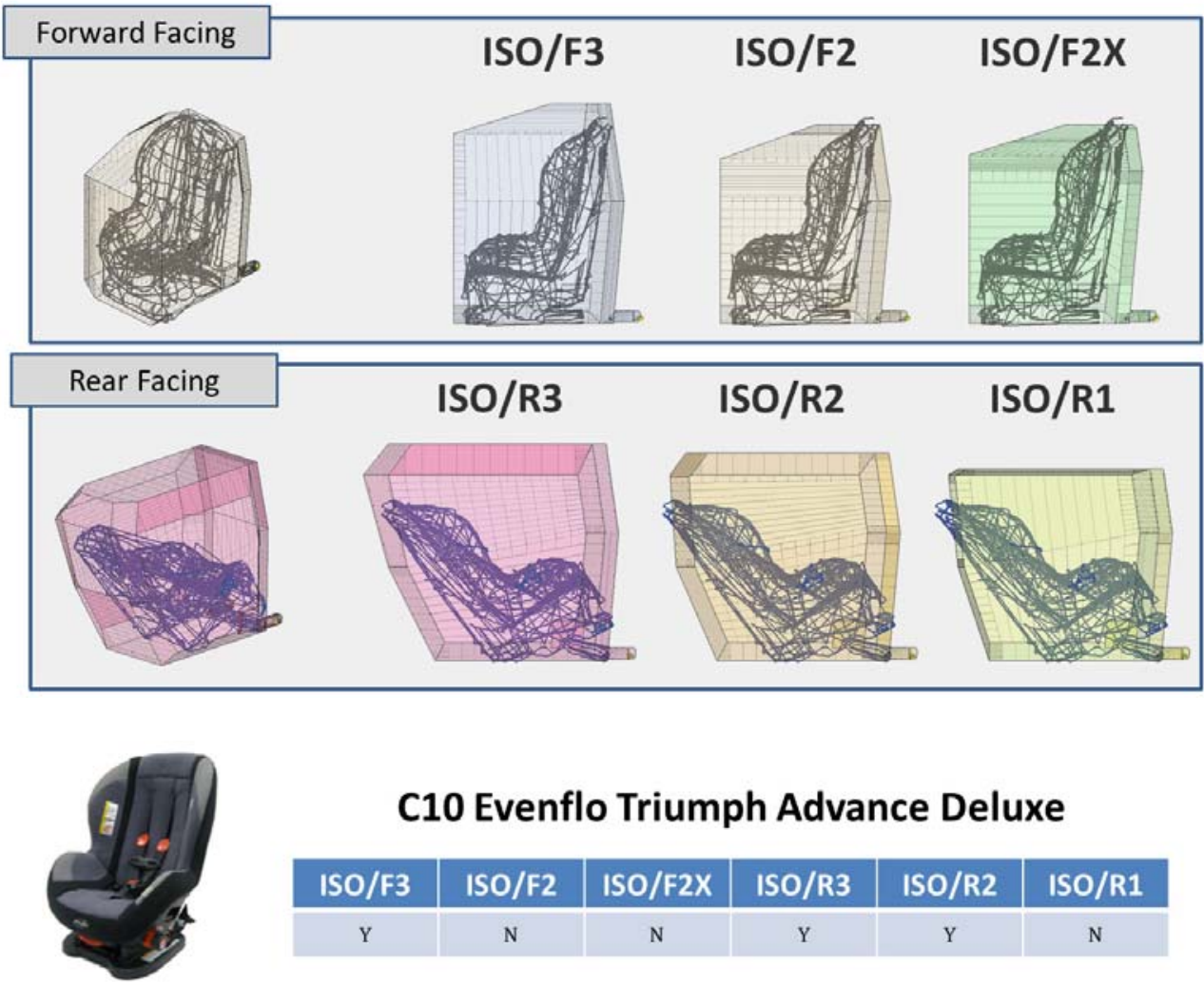

C10 Evenflo Triumph Advance Deluxe

\section{\begin{tabular}{l|l|l|l|l|l|} 
ISO/F3 & ISO/F2 & ISO/F2X & ISO/R3 & ISO/R2 & ISO/R1
\end{tabular}}

\begin{tabular}{|l|l|l|l|l|l|}
\hline $\mathrm{Y}$ & $\mathrm{N}$ & $\mathrm{N}$ & $\mathrm{Y}$ & $\mathrm{Y}$ & $\mathrm{N}$ \\
\hline
\end{tabular}
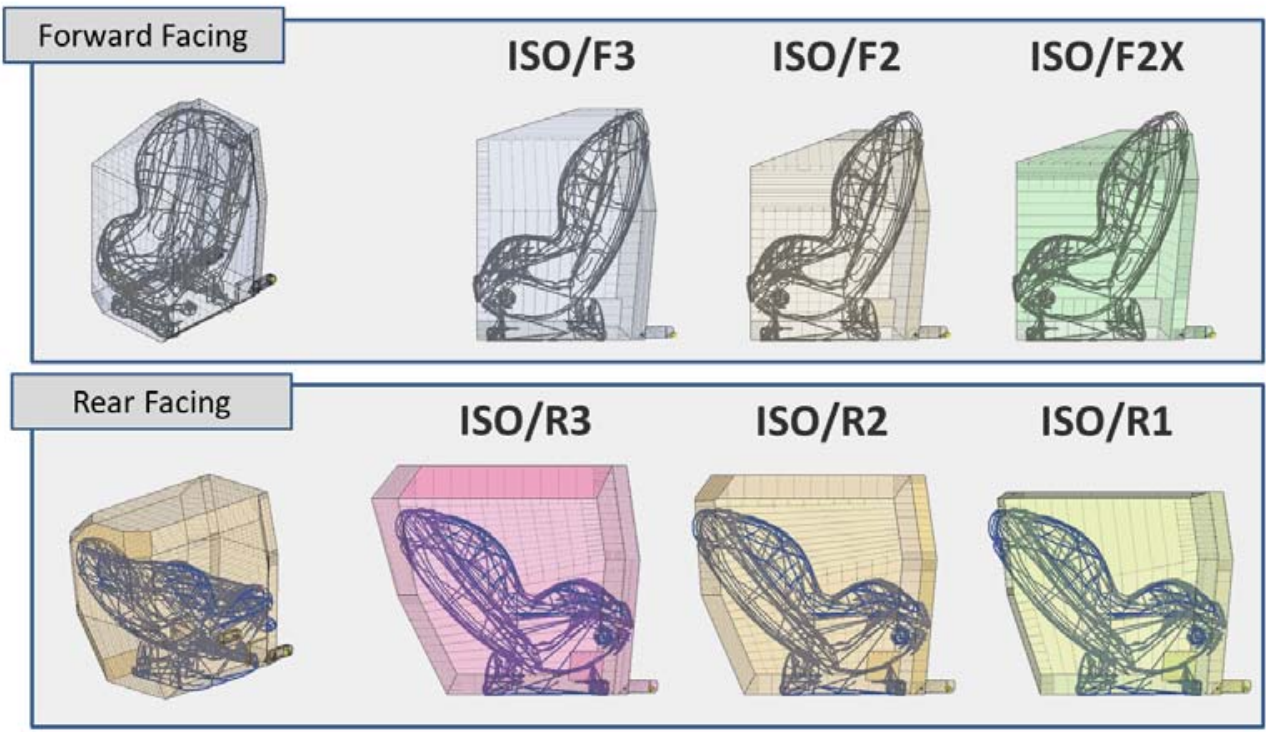

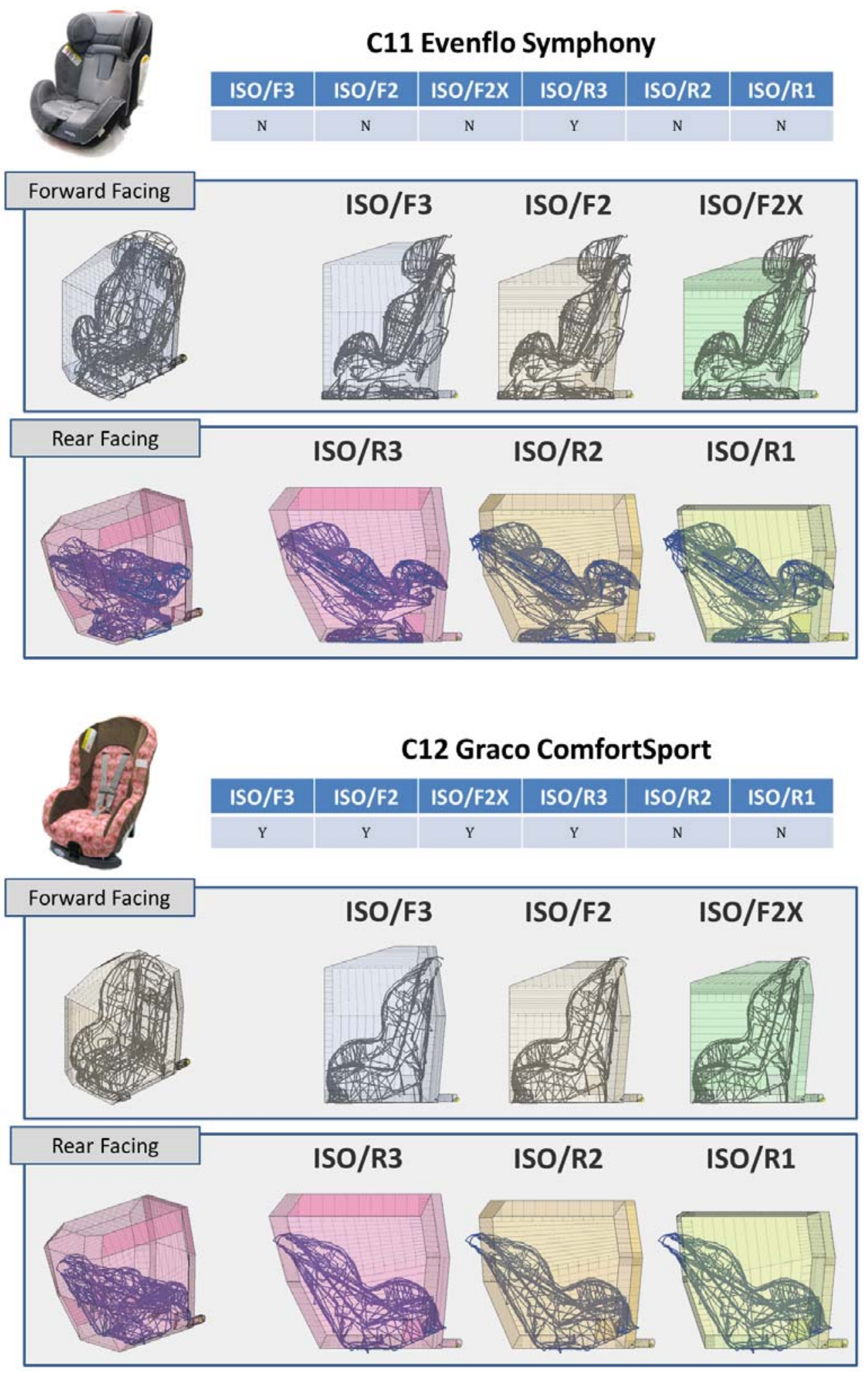


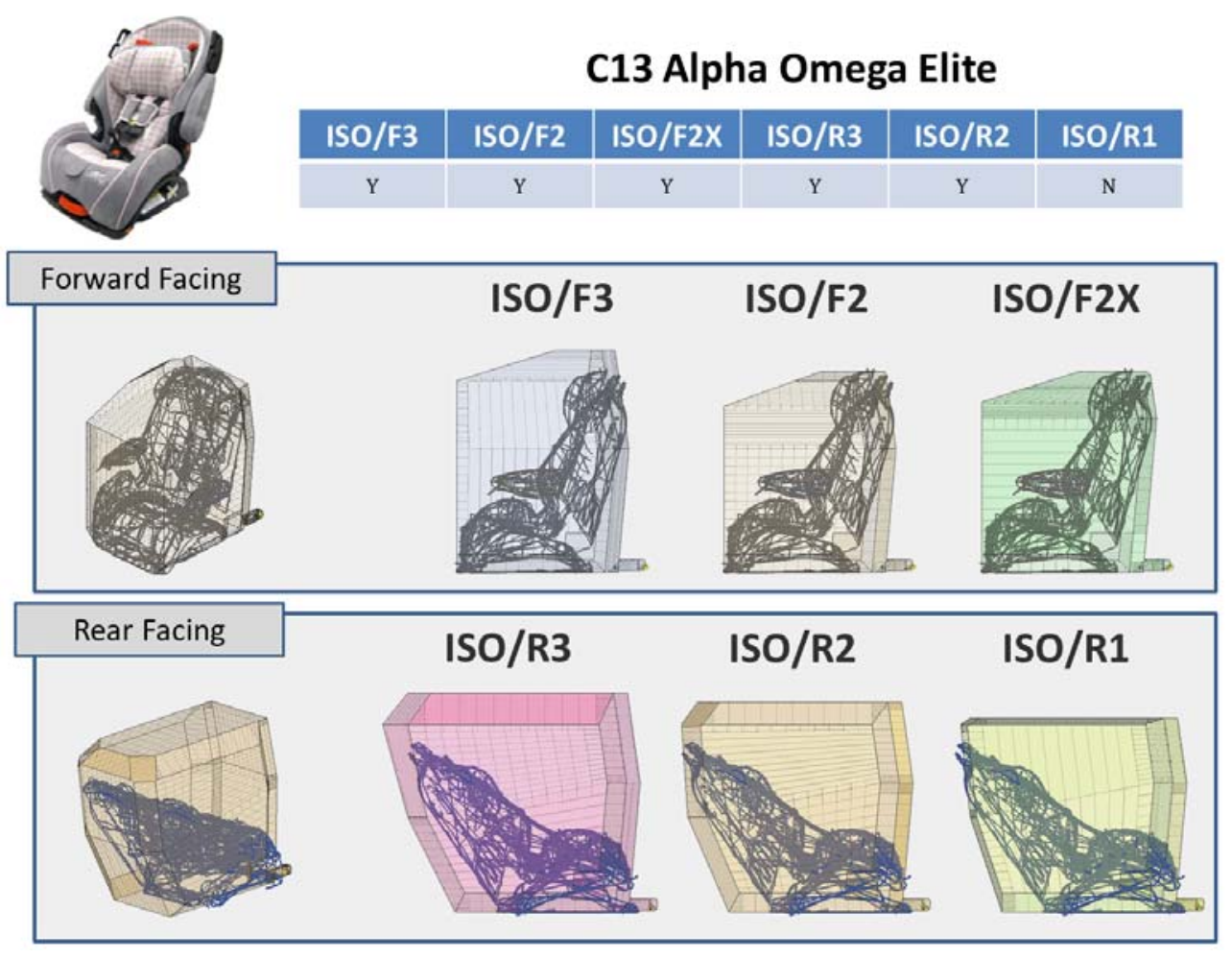

C14 Eddie Bauer Deluxe 3in1

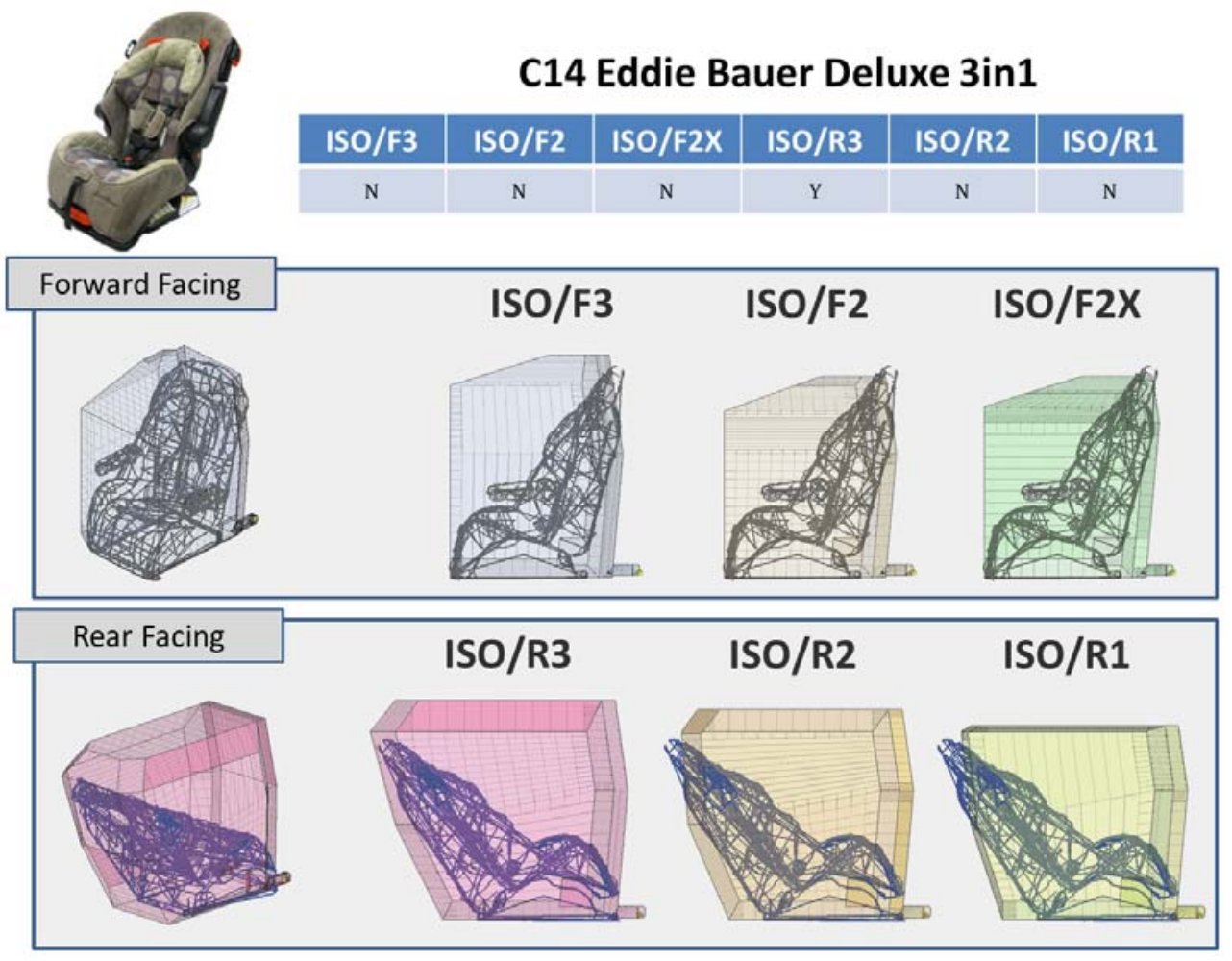




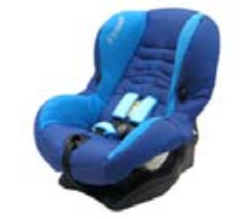

\section{C15 Dorel Maxi-Cosi Priori}

\begin{tabular}{|c|c|c|c|c|c|}
\hline ISO/F3 & ISO/F2 & ISO/F2X & ISO/R3 & ISO/R2 & ISO/R1 \\
\hline Y & Y & Y & Y & N & N \\
\hline
\end{tabular}
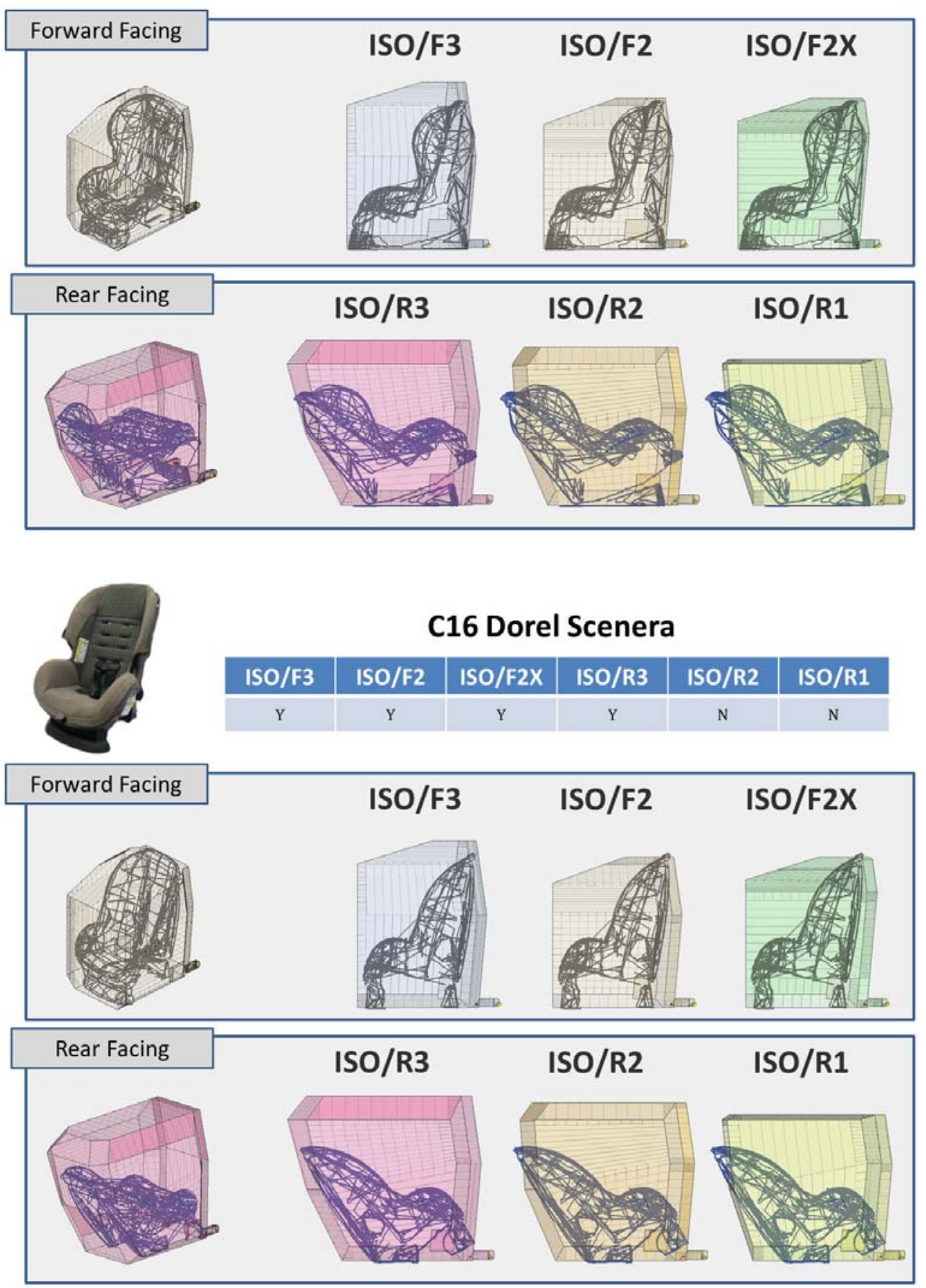

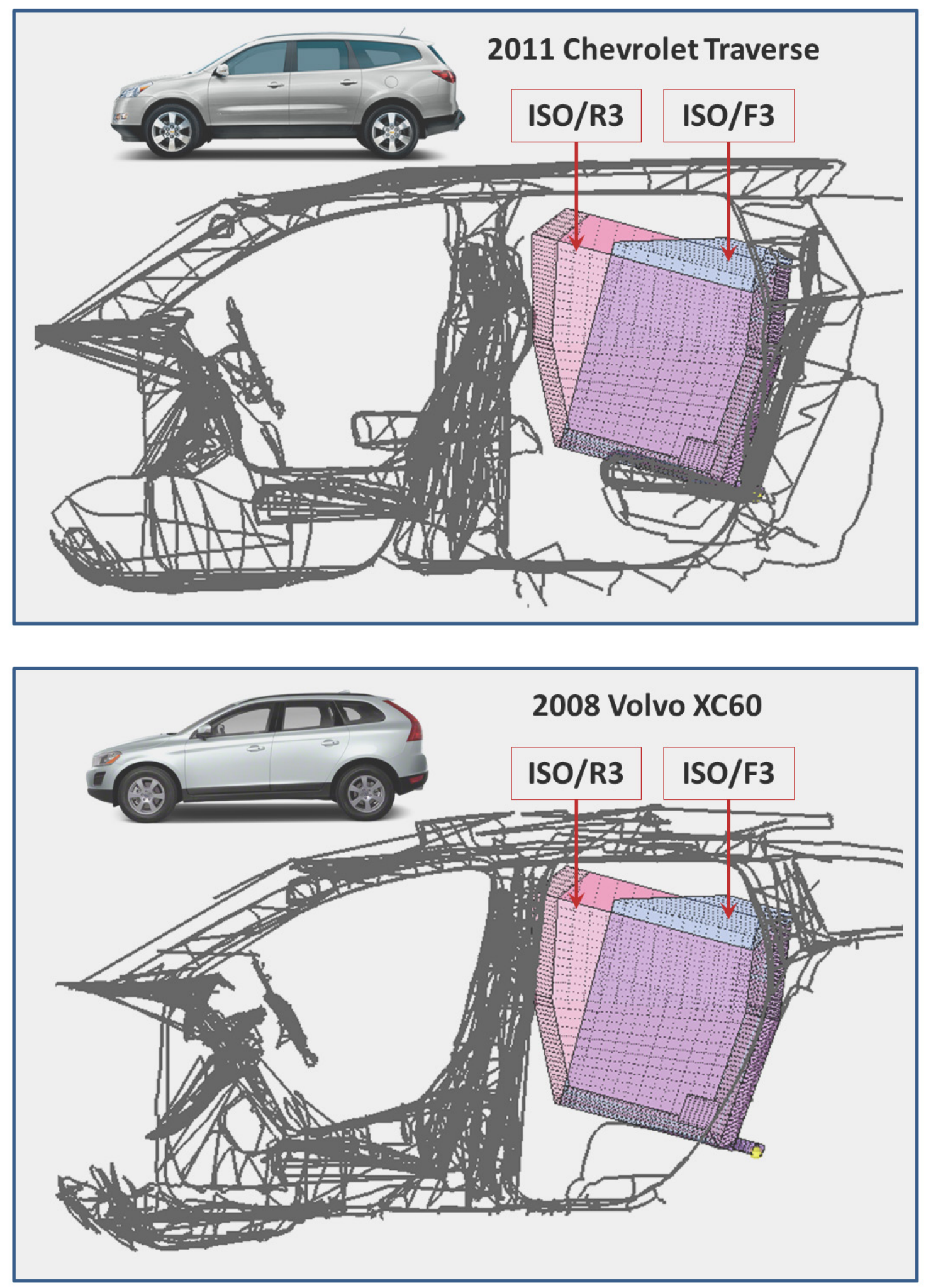

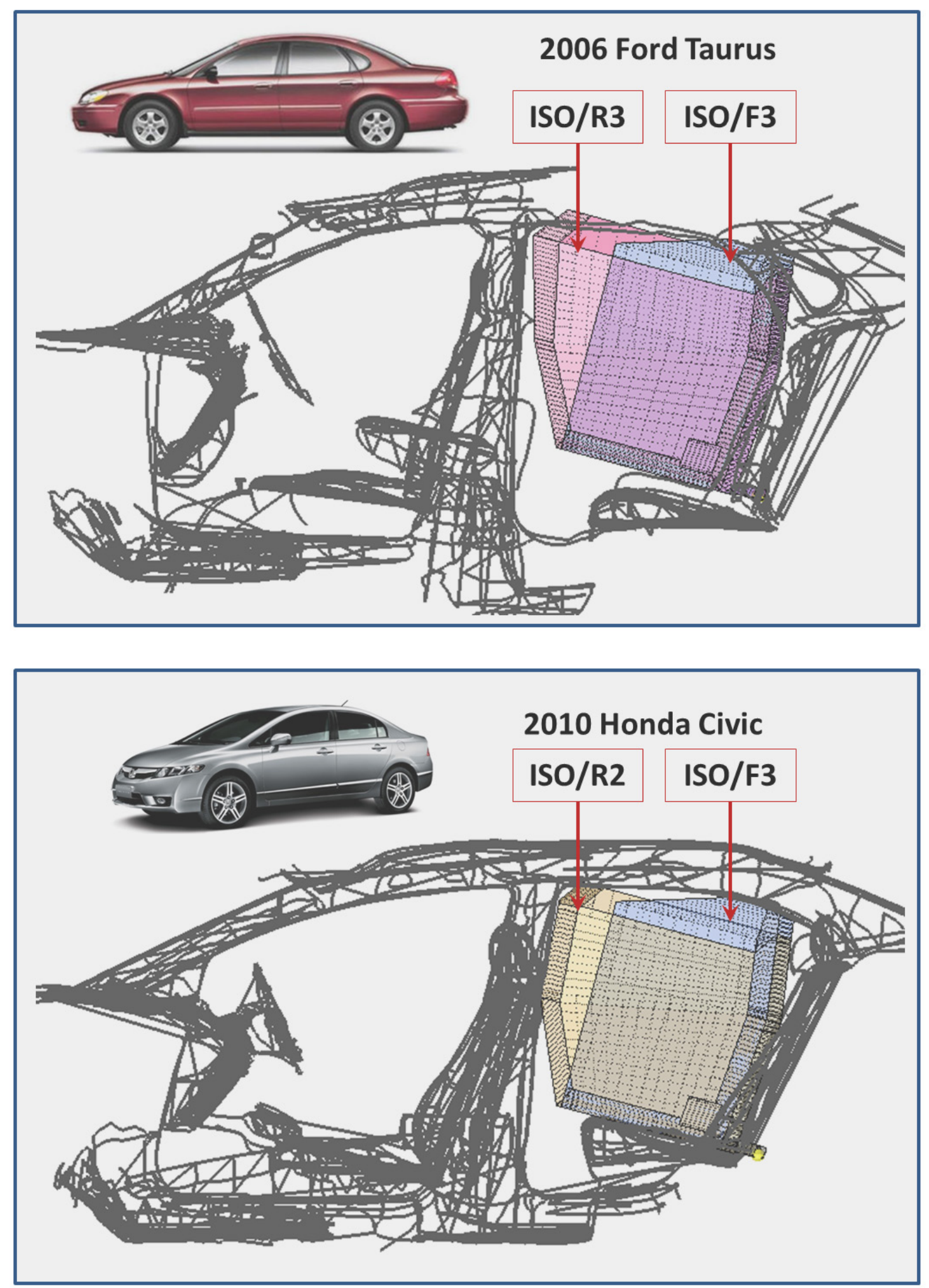

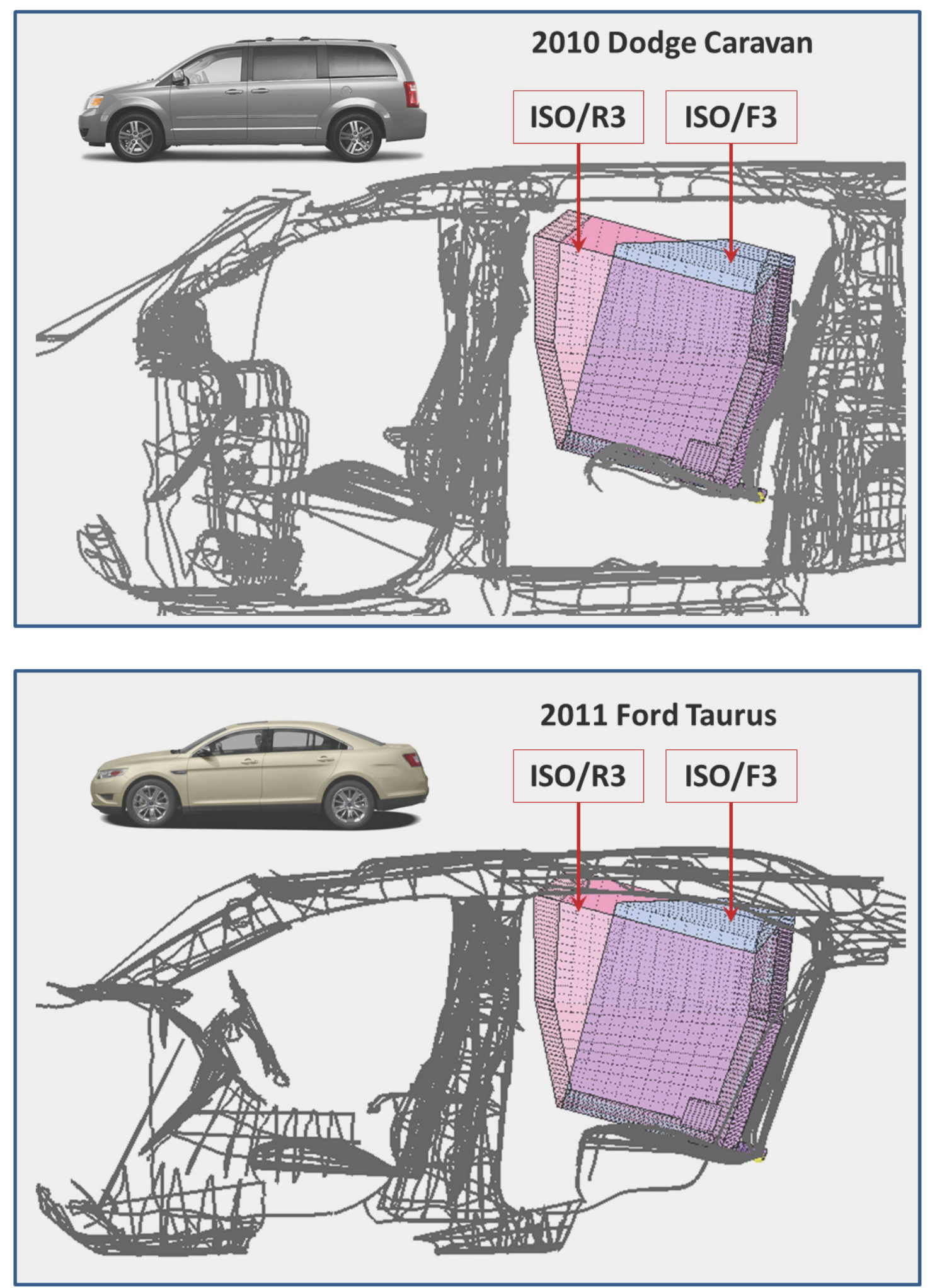

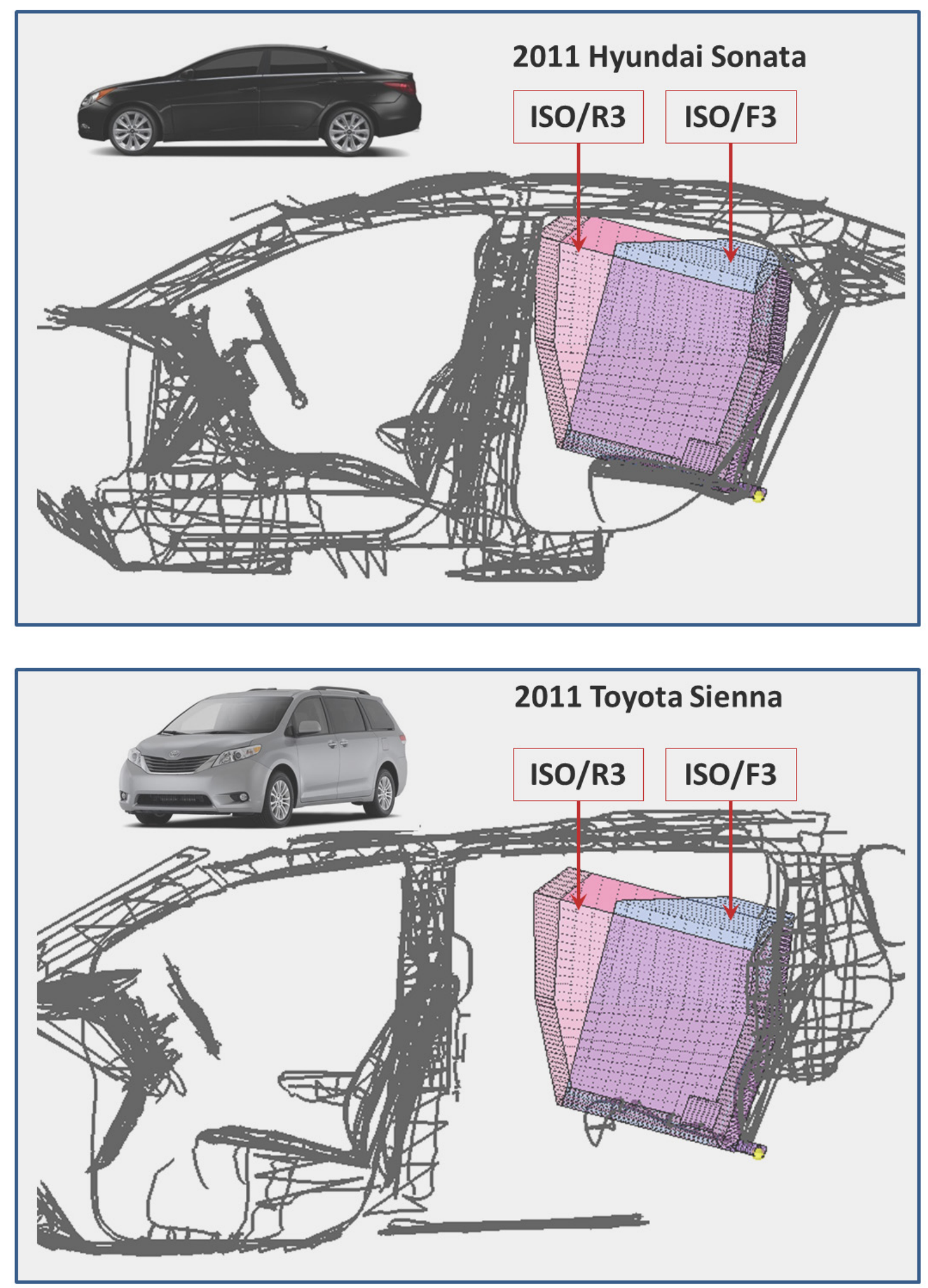

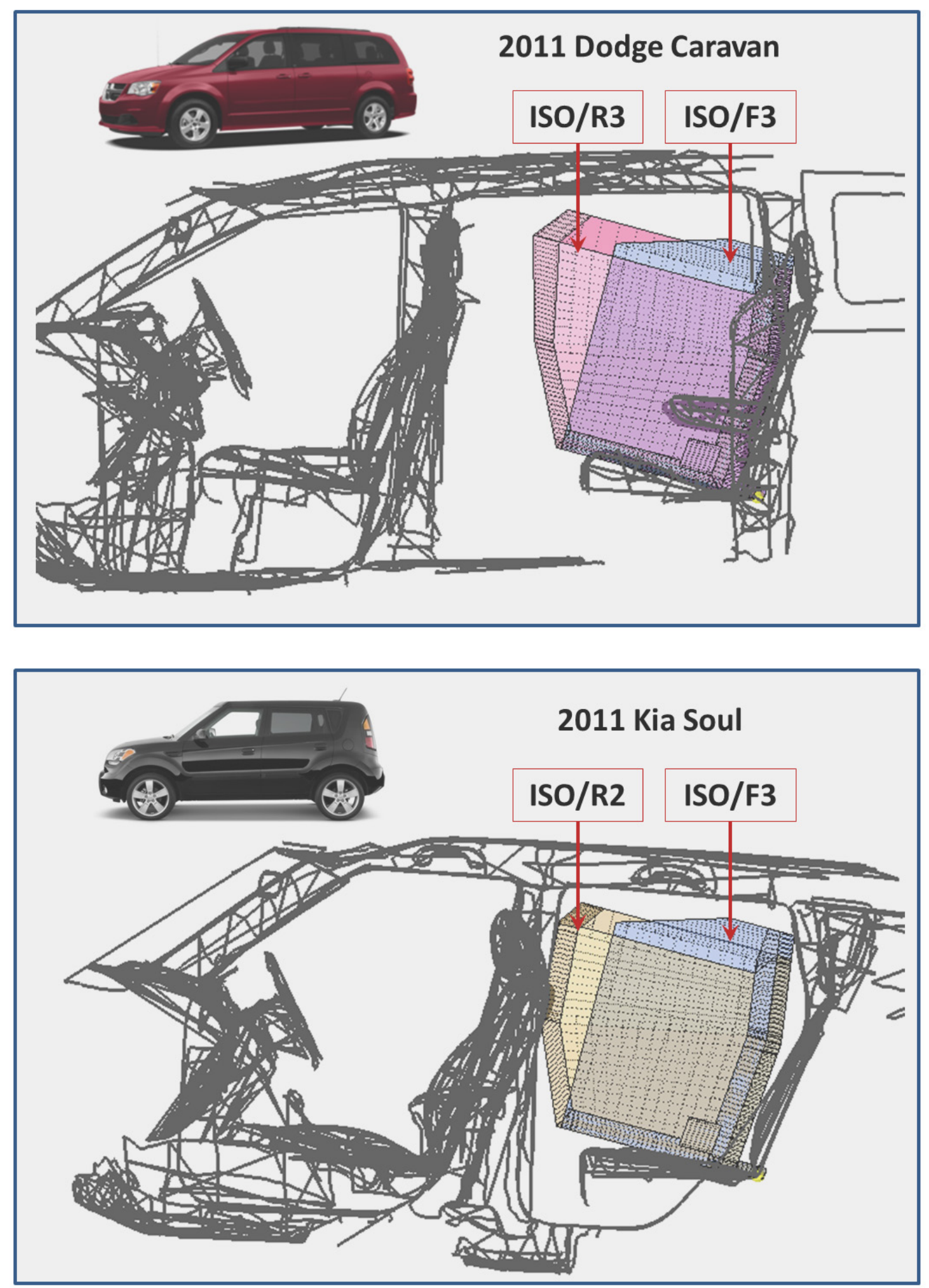

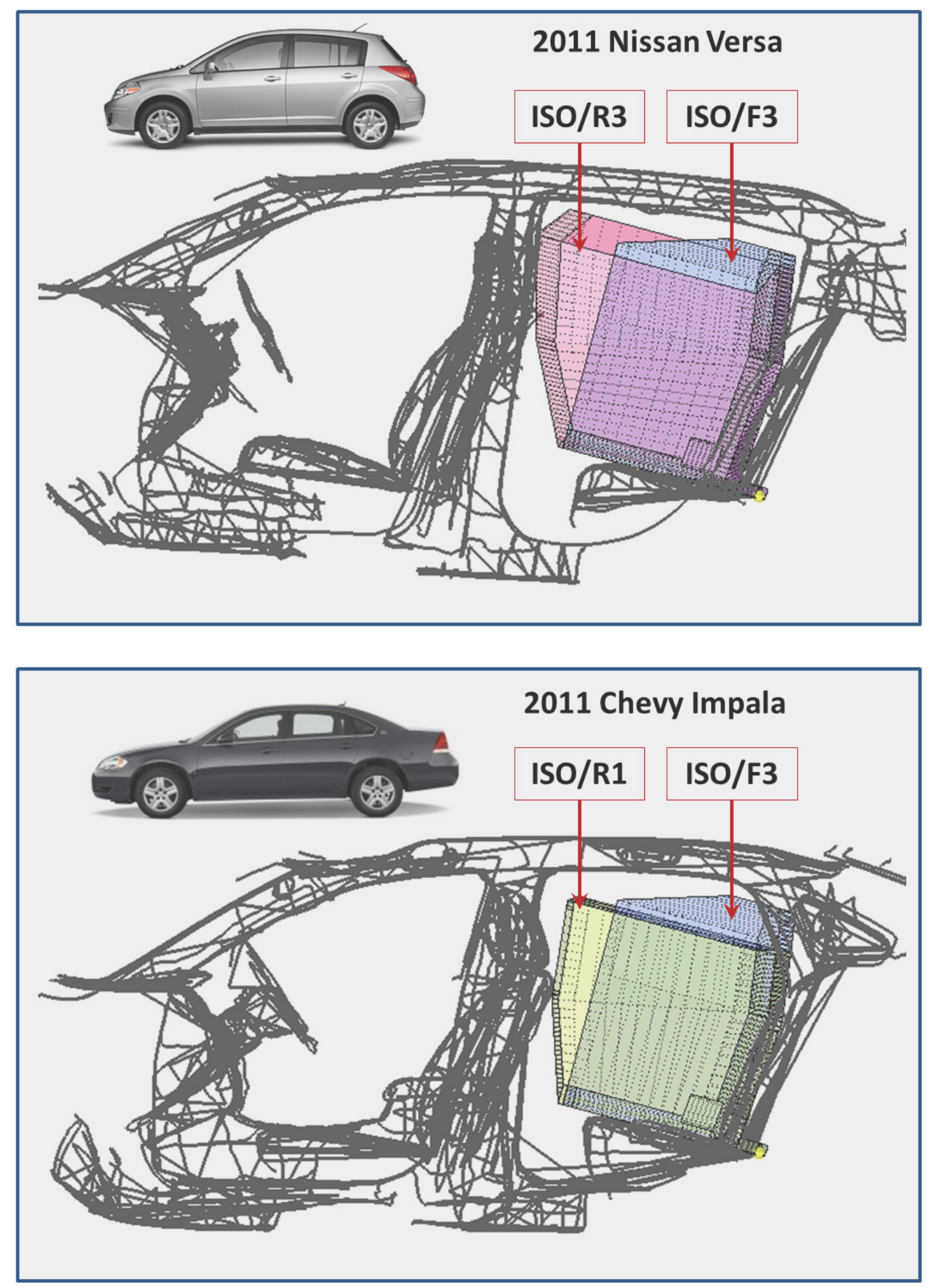

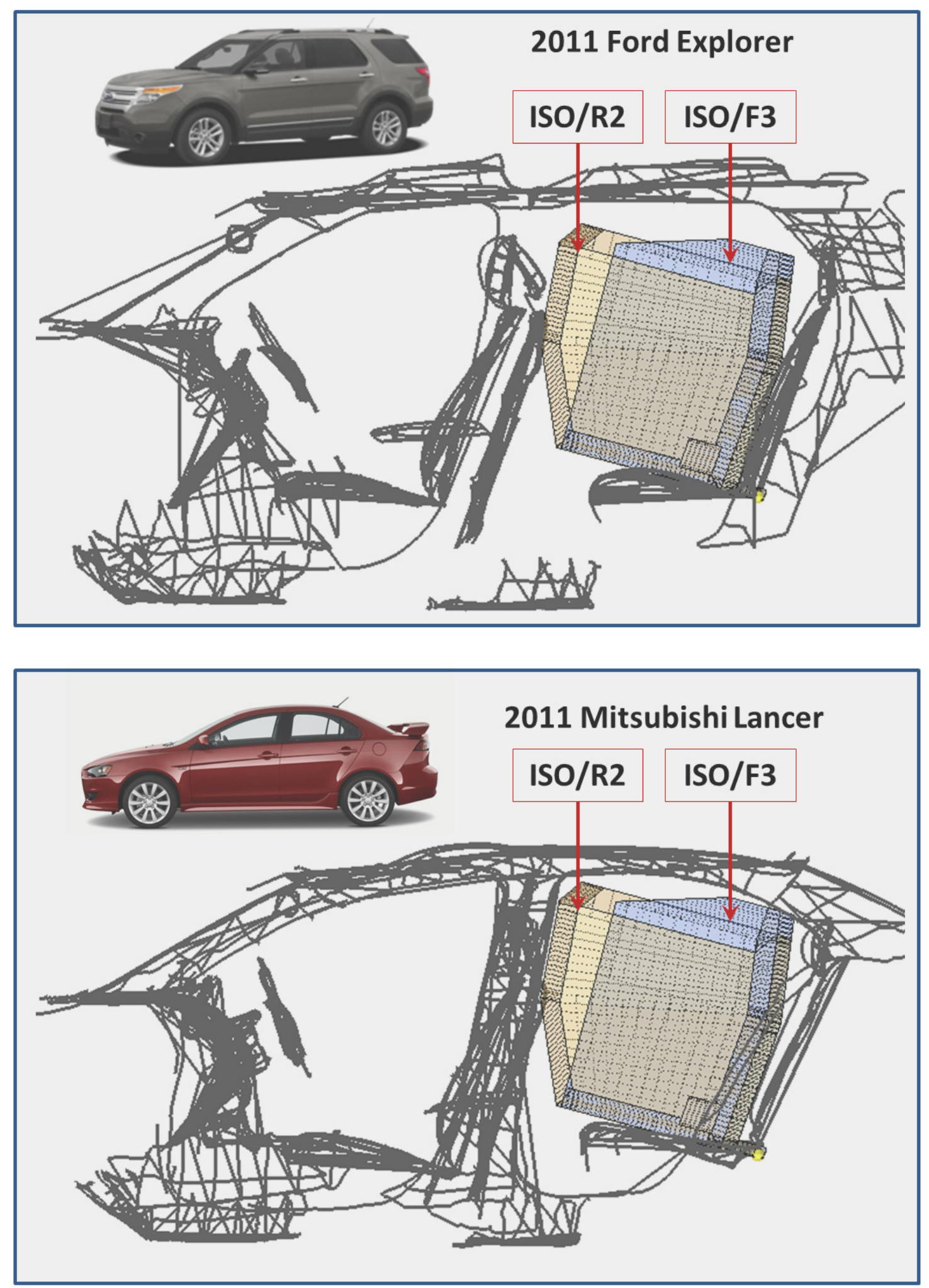

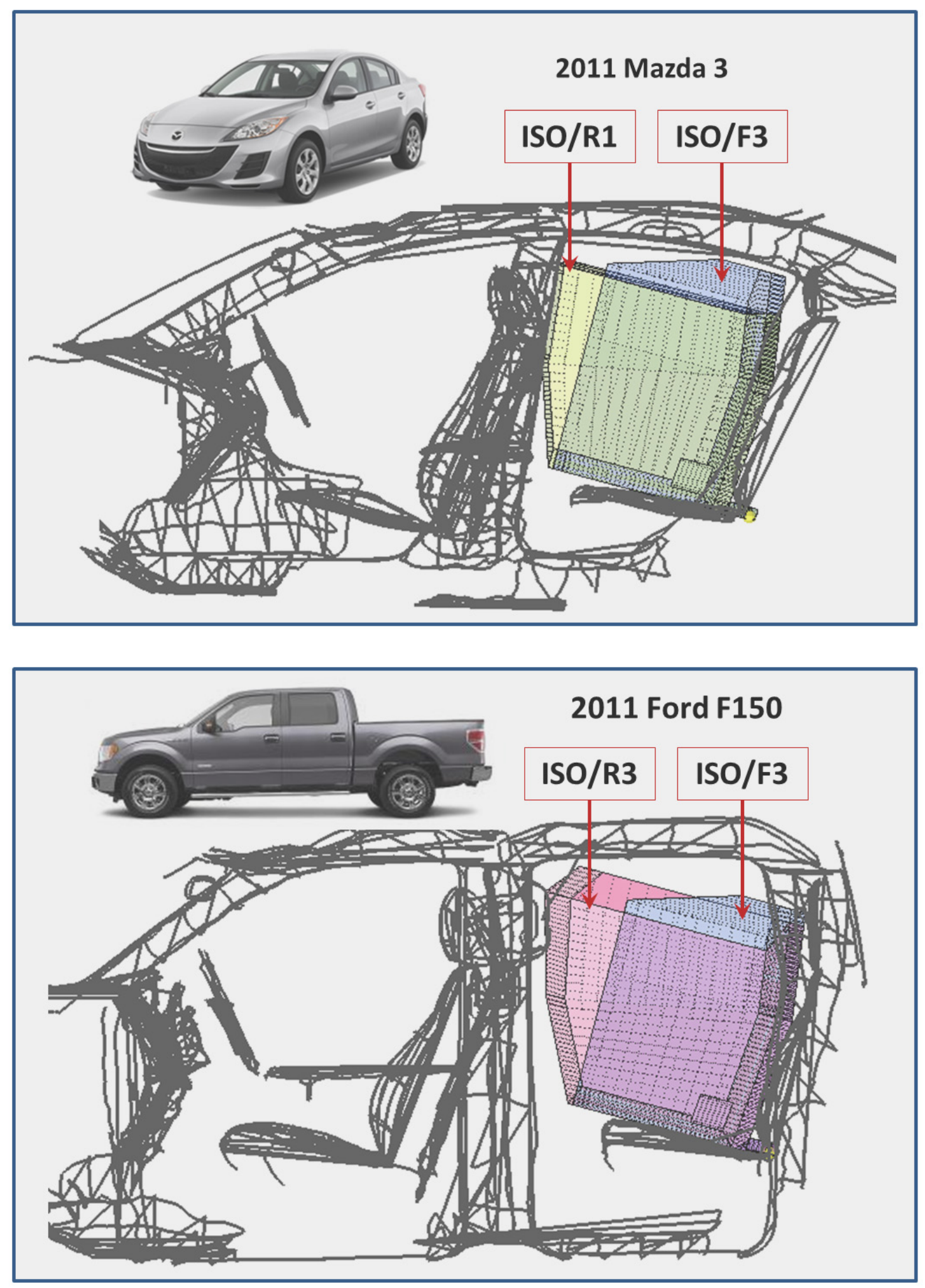

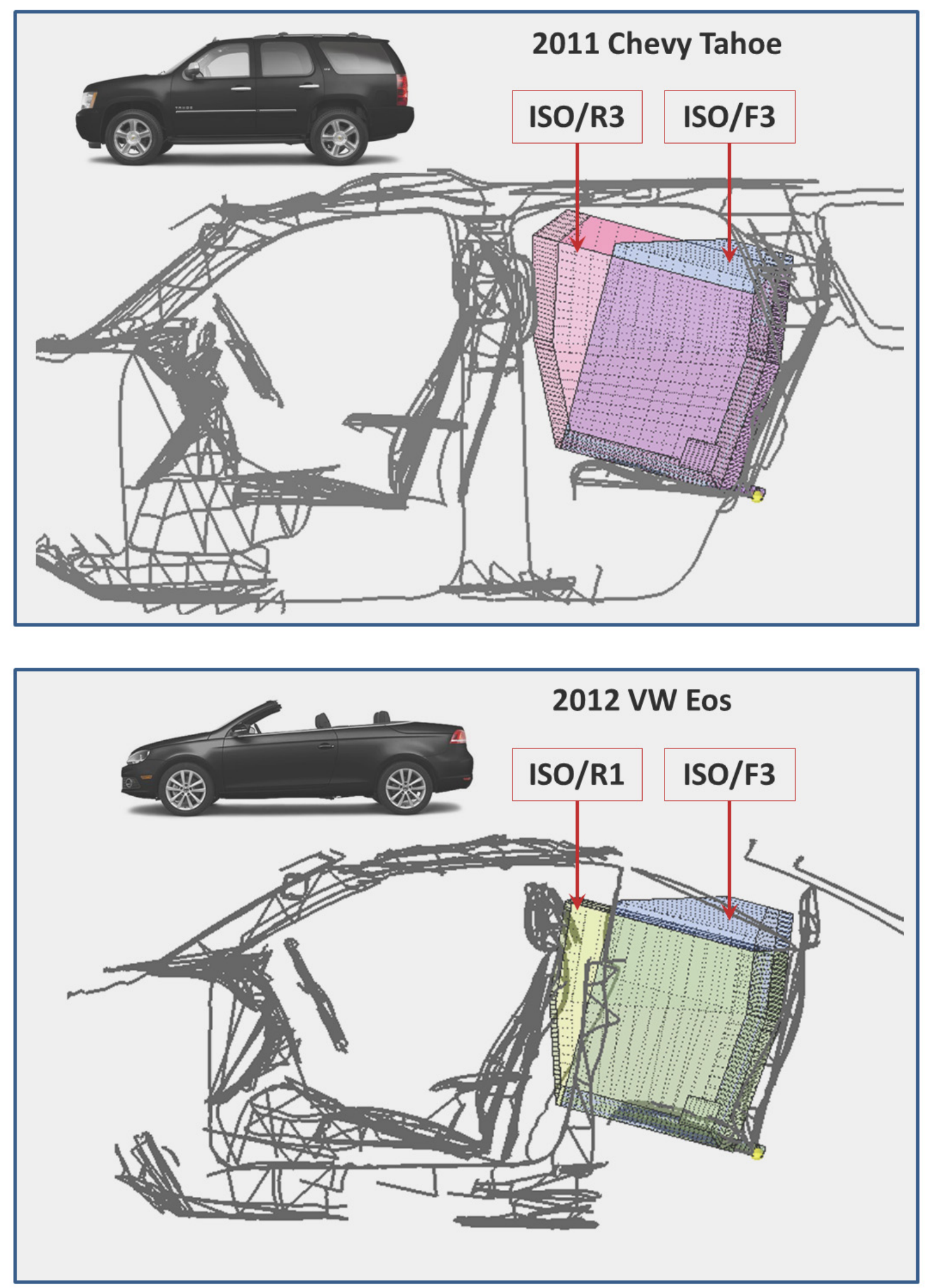

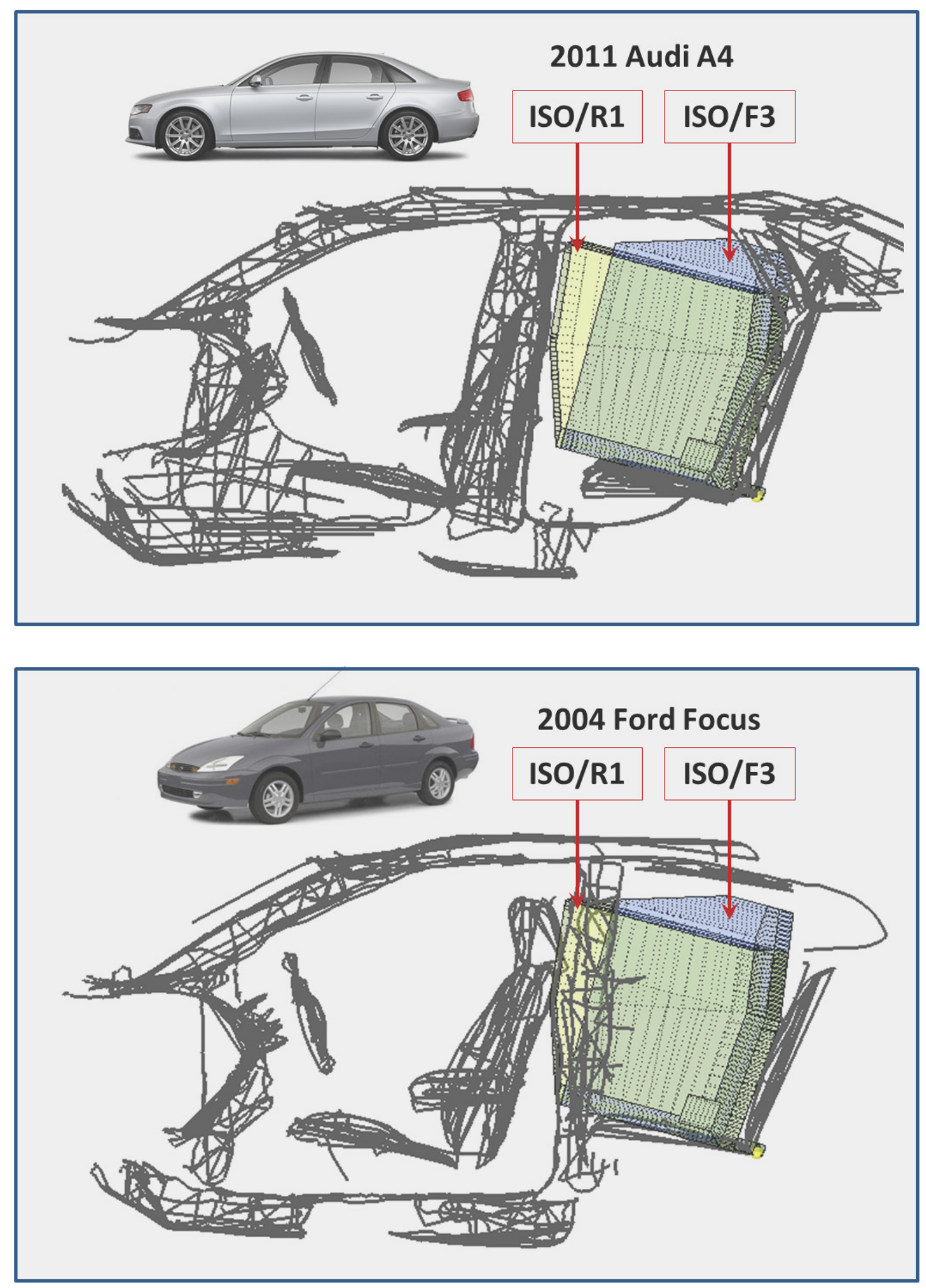

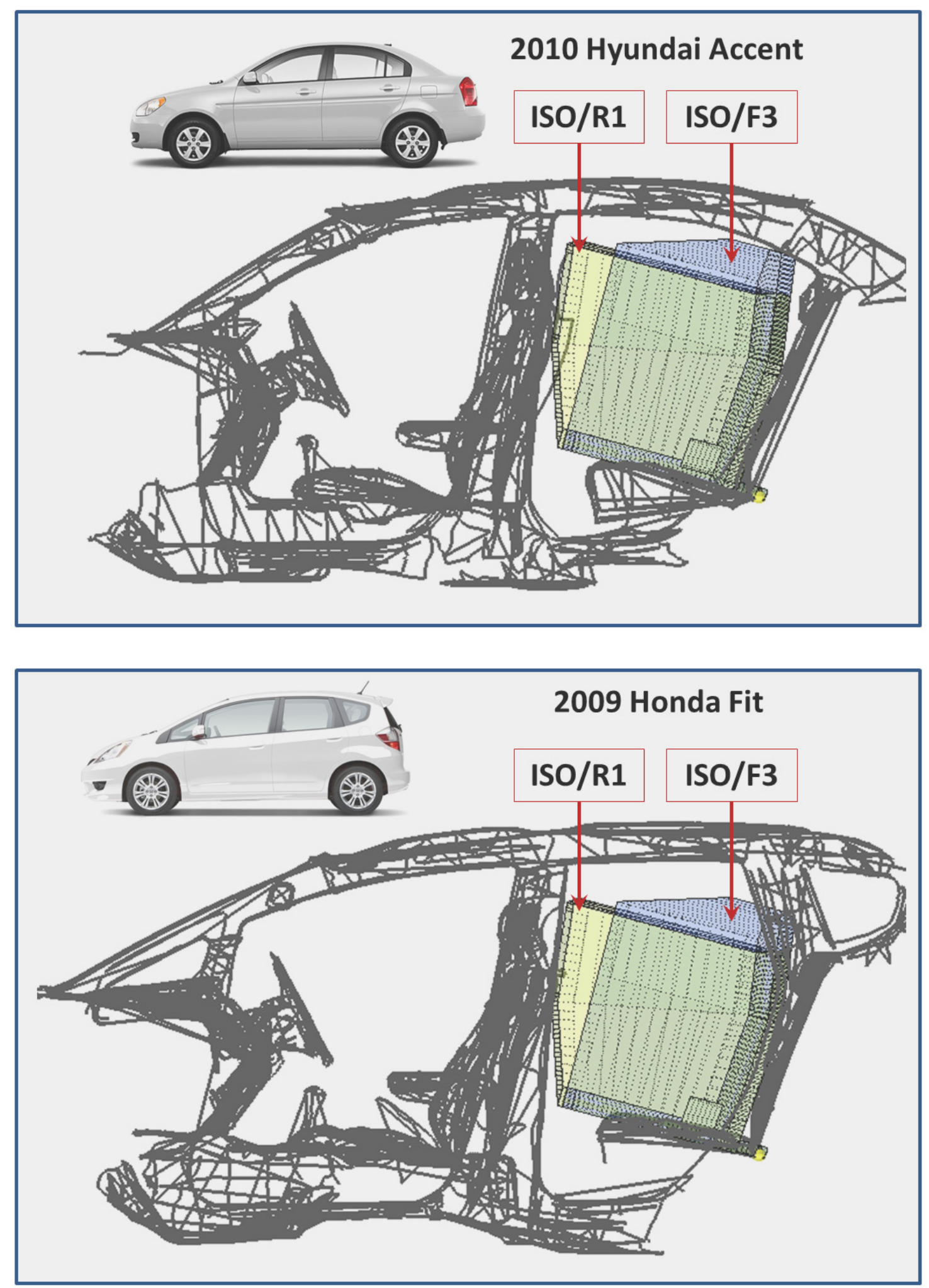

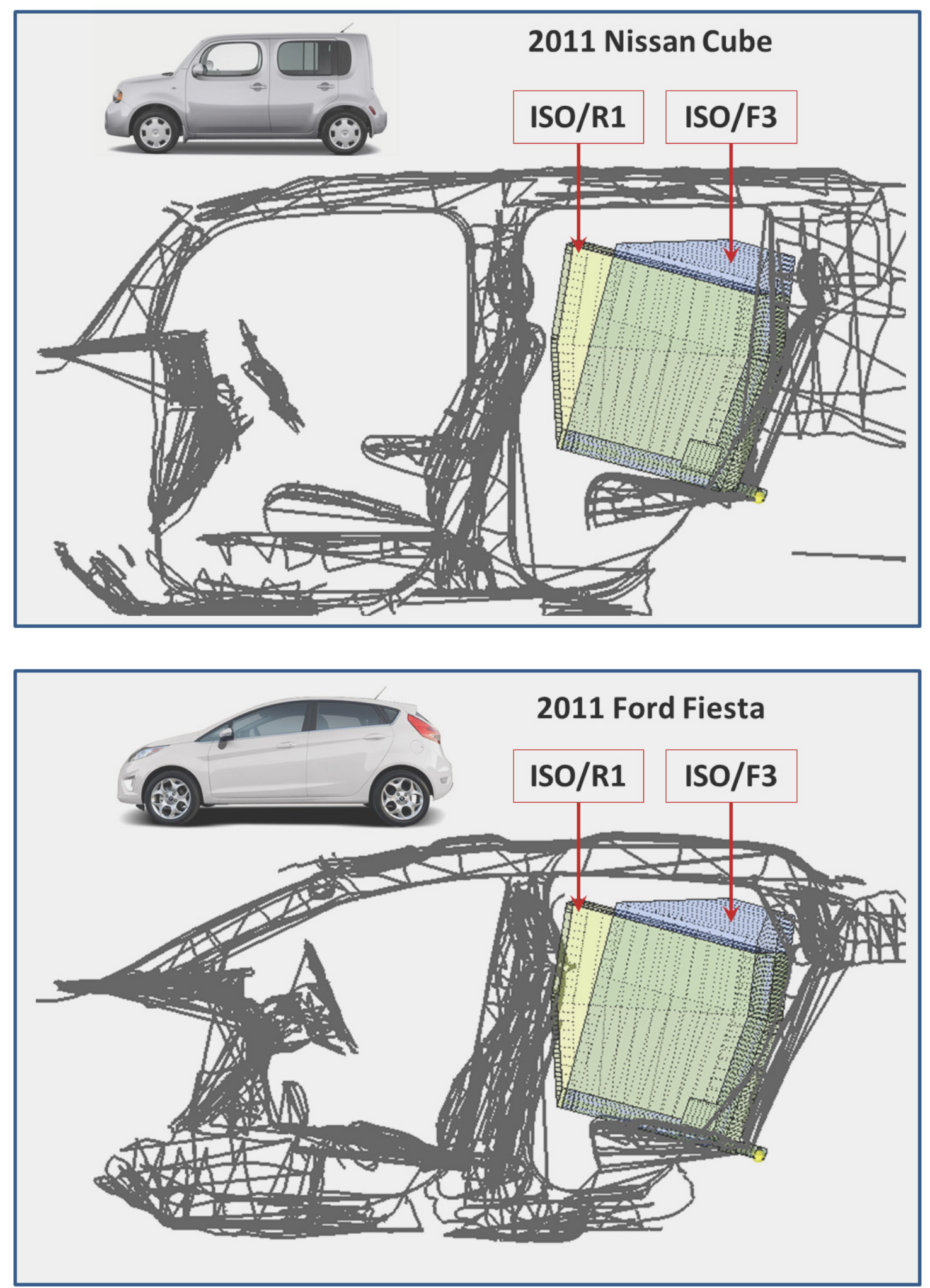

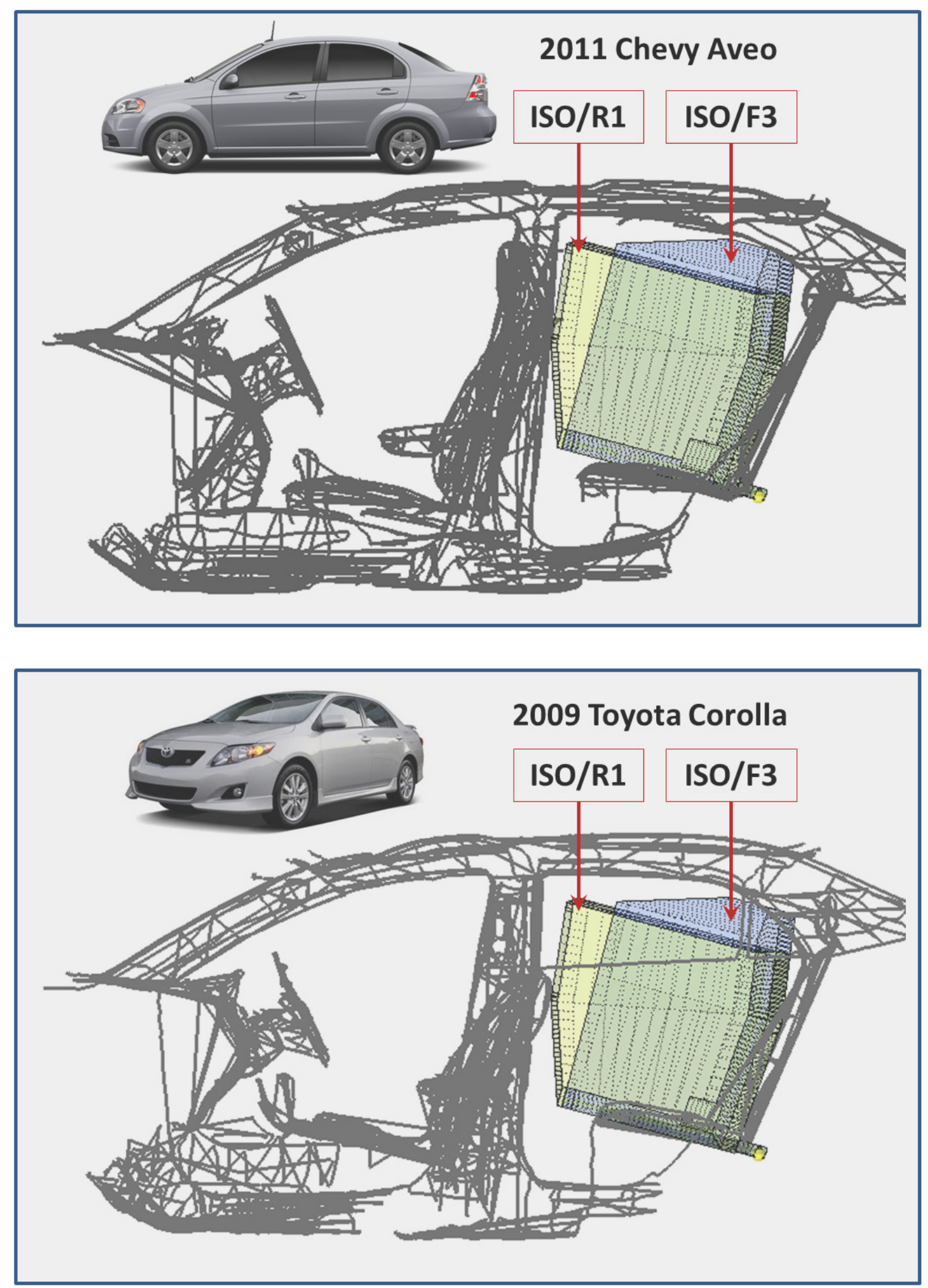
DOT HS 812106

January 2015

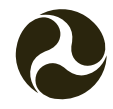

U.S. Department of Transportation

National Highway

Traffic Safety

Administration

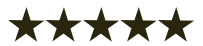

www.nhtsa.gov

11145-012715-v3 